\title{
Quantifying immediate radiative forcing by black carbon and organic matter with the Specific Forcing Pulse
}

\author{
T. C. Bond ${ }^{1}$, C. Zarzycki ${ }^{1}$, M. G. Flanner ${ }^{2}$, and D. M. Koch ${ }^{3}$ \\ ${ }^{1}$ Department of Civil and Environmental Engineering, University of Illinois at Urbana-Champaign, Urbana, Illinois, USA \\ ${ }^{2}$ Department of Atmospheric, Oceanic and Space Sciences, University of Michigan Ann Arbor, Michigan, USA \\ ${ }^{3}$ NASA Goddard Institute for Space Studies, Columbia University, New York, USA
}

Received: 18 May 2010 - Published in Atmos. Chem. Phys. Discuss.: 28 June 2010

Revised: 12 November 2010 - Accepted: 11 January 2011 - Published: 16 February 2011

\begin{abstract}
Climatic effects of short-lived climate forcers (SLCFs) differ from those of long-lived greenhouse gases, because they occur rapidly after emission and because they depend upon the region of emission. The distinctive temporal and spatial nature of these impacts is not captured by measures that rely on global averages or long time integrations. Here, we propose a simple measure, the Specific Forcing Pulse (SFP), to quantify climate warming or cooling by these pollutants, where we define "immediate" as occurring primarily within the first year after emission. SFP is the amount of energy added to or removed from a receptor region in the Earth-atmosphere system by a chemical species, per mass of emission in a source region. We limit the application of SFP to species that remain in the atmosphere for less than one year. Metrics used in policy discussions, such as total forcing or global warming potential, are easily derived from SFP. However, SFP conveys purely physical information without incurring the policy implications of choosing a time horizon for the global warming potential.

Using one model (Community Atmosphere Model, or CAM), we calculate values of SFP for black carbon (BC) and organic matter (OM) emitted from 23 source-region combinations. Global SFP for both atmosphere and cryosphere impacts is divided among receptor latitudes. SFP is usually greater for open-burning emissions than for energy-related (fossil-fuel and biofuel) emissions because of the timing of emission. Global SFP for BC varies by about $45 \%$ for energy-related emissions from different regions. This variation would be larger except for compensating effects. When emitted aerosol has larger cryosphere forcing, it often has lower atmosphere forcing because of less deep convection and a shorter atmospheric lifetime.
\end{abstract}

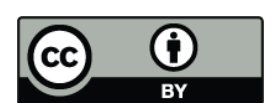

Correspondence to: T. C. Bond (yark@illinois.edu)
A single model result is insufficient to capture uncertainty. We develop a best estimate and uncertainties for SFP by combining forcing results from 12 additional models. We outline a framework for combining a large number of simple models with a smaller number of enhanced models that have greater complexity. Adjustments for black carbon internal mixing and for regional variability are discussed. Emitting regions with more deep convection have greater model diversity. Our best estimate of global-mean SFP is $+1.03 \pm 0.52 \mathrm{GJ} \mathrm{g}^{-1}$ for direct atmosphere forcing of black carbon, $+1.15 \pm 0.53 \mathrm{GJ} \mathrm{g}^{-1}$ for black carbon including direct and cryosphere forcing, and $-0.064(-0.02$, $-0.13) \mathrm{GJg}^{-1}$ for organic matter. These values depend on the region and timing of emission. The lowest OM:BC mass ratio required to produce a neutral effect on top-ofatmosphere direct forcing is 15:1 for any region. Any lower ratio results in positive direct forcing. However, important processes, particularly cloud changes that tend toward cooling, have not been included here.

Global-average SFP for energy-related emissions can be converted to a 100-year GWP of about $740 \pm 370$ for BC without snow forcing, and $830 \pm 440$ with snow forcing. 100-year GWP for OM is $-46(-18,-92)$. Best estimates of atmospheric radiative impact (without snow forcing) by black and organic matter are $+0.47 \pm 0.26 \mathrm{~W} \mathrm{~m}^{-2}$ and -0.17 $(-0.07,-0.35) \mathrm{W} \mathrm{m}^{-2}$ for $\mathrm{BC}$ and $\mathrm{OM}$, respectively, assuming total emission rates of 7.4 and $45 \mathrm{Tg} \mathrm{yr}^{-1}$. Anthropogenic forcing is $+0.40 \pm 0.18 \mathrm{~W} \mathrm{~m}^{-2}$ and $-0.13(-0.05$, $-0.25) \mathrm{W} \mathrm{m}^{-2}$ for $\mathrm{BC}$ and $\mathrm{OM}$, respectively, assuming anthropogenic emission rates of 6.3 and $32.6 \mathrm{Tg} \mathrm{yr}^{-1}$. Black carbon forcing is only $18 \%$ higher than that given by the Intergovernmental Panel on Climate Change (IPCC), although the value presented here includes enhanced absorption due to internal mixing.

Published by Copernicus Publications on behalf of the European Geosciences Union. 


\section{Introduction}

Atmospheric burdens of chemical species with short atmospheric lifetimes respond rapidly to changes in emission. Many of these species, such as aerosols or the precursors of ozone, affect the Earth's radiative balance, either directly or by interacting with atmospheric chemistry. The radiative response to emissions of these "short-lived climate forcers" (SLCFs) differs greatly from the response to longlived greenhouse gases, for which atmospheric burdens and the resulting forcing lag emission changes by decades.

Because mitigation of SLCFs could rapidly reduce climate warming, the possibility of decreasing them has engendered a flurry of interest (Hansen et al., 2000; Grieshop et al., 2009). SLCFs emitted from some locations also impact sensitive regions such as the Arctic (Quinn et al., 2008). However, the impact and, hence, the value of such regionally-dependent reductions has been difficult to express using traditional measures of climate change. For example, global warming potentials (GWPs) are discussed for purposes of trading, and have been estimated for some shortlived species, but they do not communicate explicit information on either the timing or location of climate impact.

In this paper, we propose a method for quantifying temporal and regional climate impacts of SLCFs, a first step toward valuation. In Sect. 2, we introduce the Specific Forcing Pulse (SFP) to quantify both location and immediacy. We do not propose that SFP should be used to equate the impacts of greenhouse gases and SLCFs, which operate over fundamentally different temporal and spatial scales. Nevertheless, in Sect. 2, we also discuss the connection between SFP and other common measures of climate impact, such as GWPs and total radiative forcing.

Section 3 presents values of SFP for black carbon (BC) and organic matter $(\mathrm{OM})$ aerosol emitted from several source regions, derived using one chemical transport model. We discuss reasons for differences among regions. We also acknowledge that reliance on a single model is insufficient. In Sect. 4, we therefore propose a method of deriving a best estimate and uncertainties for SFP by adjusting our SFP with an ensemble of other modeled values. Finally, Sect. 5 compares the values derived in this work with previous estimates of radiative forcing and GWP.

\section{Specific Forcing Pulse}

\subsection{The distinct nature of immediate forcing}

We define "immediate forcing" as a condition in which there is no delay between emission and the delivery of the entire forcing impact attributable to that emission. Although forcing is never truly immediate, we argue that it may be considered so when the entire impact occurs within a very short period after emission. The definition of "short" is ar- bitrary, but we propose that one year is a reasonable time limit. With this definition, species with e-folding lifetimes of four months produce immediate forcing, because $95 \%$ of the forcing occurs within one year after emission. One might argue with this choice of time limit: why not three, five, or ten years? However, this selection is not important. Climateforcing agents that have major impacts in the current Earth system happen to have lifetimes that are either shorter than one year or much longer. A one-year time limit effectively divides species that have impacts only in the very near future and those for which accumulated burdens are important.

Changes in radiative forcing can often be represented using just a few characteristic time scales. For example, Wild et al. (2001) showed that a pulse of emitted nitrogen oxide caused climate forcing through its interactions with tropospheric ozone (lifetime less than one year) and with methane (lifetime greater than 8 years). Like species that interact solely with the ozone chemical system, aerosols alter forcing shortly after emission, and this forcing dies away within a short time when the species no longer interact with radiation.

Figure 1 shows the time evolution of forcing and climate response by pulse emissions of different hypothetical species. The left panels show an SLCF with an $e$-folding time of four months. Middle panels show a substance with a lifetime similar to that of methane (9 years). The right panels show a substance with an atmospheric decay similar to that of $\mathrm{CO}_{2}$. The top panels in Figure 1 are of arbitrary scale and indicate that all species here are introduced as pulse emissions. The middle panels show forcing by each species, with magnitudes scaled so that the integrated forcing over 100 years is identical for each substance. Compared with the longerlived species, forcing by SLCFs appears as a pulse of forcing or a burst of energy, although its lifetime is non-zero. Response to this immediate forcing is very different from response to longer-lived species. The bottom graphs in Fig. 1 show climate response to each time series of forcing, using the equations provided by Boucher and Reddy (2008). The figures show that the temporal evolution of forcing affects temperature response to a pulse emission. (For this reason, Global Temperature Potentials differ from Global Warming Potentials; see Shine et al., 2005).

Because the timing of forcing is important, it is worthwhile to conduct separate investigations for species that have distinctly different time scales. In this paper, we explore methods of quantifying the impacts of climate-forcing agents that provide immediate forcing.

\subsection{Regional dependence of forcing}

The short lifetime of SLCFs has another important consequence: atmospheric concentrations of SLCFs are extremely heterogeneous and are concentrated around source regions. The magnitude and location of impact therefore depend upon the source region (Berntsen et al., 2006). Figure 2 demonstrates this fact by comparing forcing by $\mathrm{BC}$ emitted from 

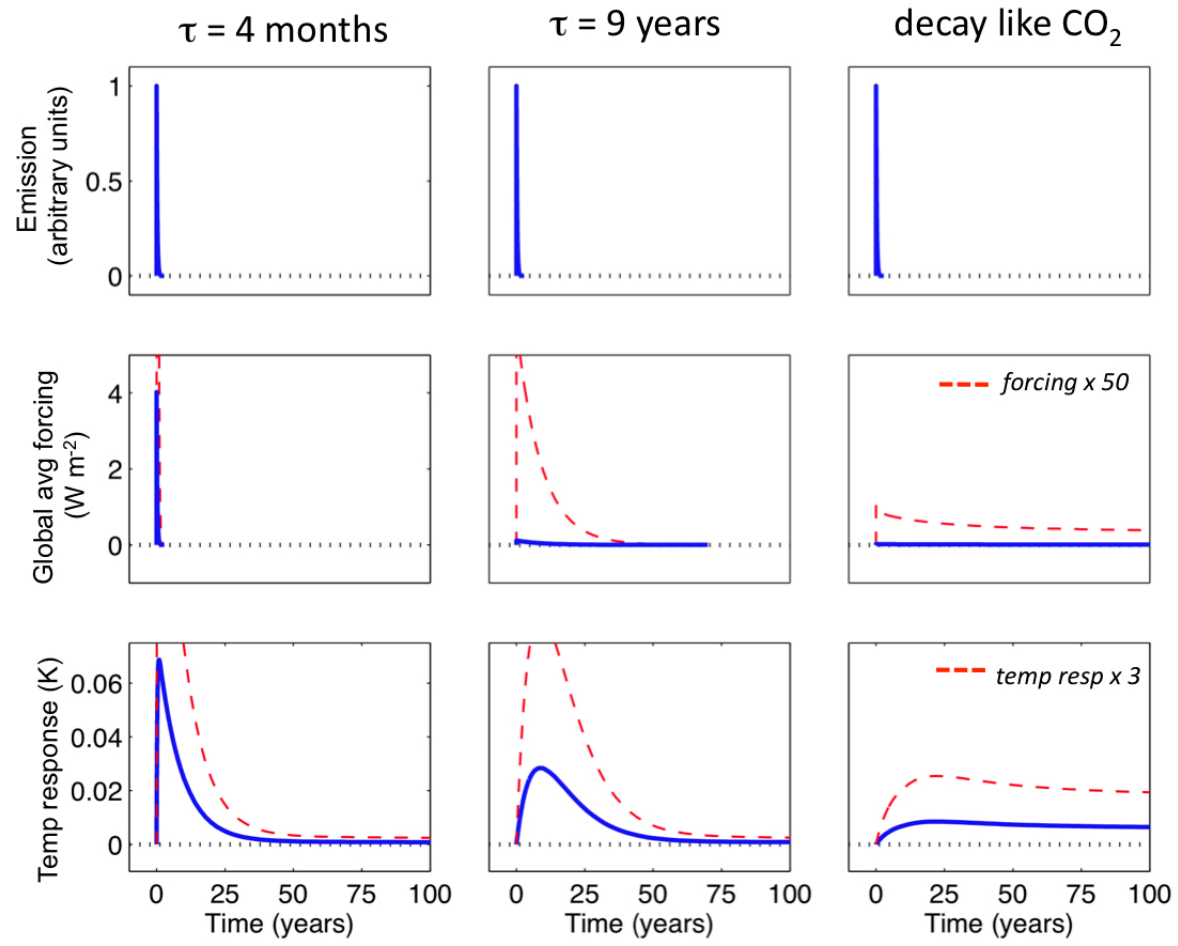

Fig. 1. Forcing and response to pulse emissions of hypothetical substances with different atmospheric lifetimes. Each trace is discontinued when the signal drops below $10^{-5}$ of the peak value of the short-lived forcer. Forcing (middle panels) has been scaled so that the area under each of three curves is identical over 100 years. Dashed red trace shows forcing value times 50 to show more detail in the time dependence. Temperature response (lower panels) is estimated with the relationship and parameters given by Boucher and Reddy (2007), and assumes that spatial dependence of forcing is similar to that of $\mathrm{CO}_{2}$.

the United States and from Africa. (The model used to create this figure is discussed further in Sect. 3).

The forcing exerted upon specific regions of interest (receptor regions) also depends on the emitting region. Here, we choose latitude bands as the receptor regions, and these are shown in Fig. 2 with dashed lines. Hansen et al. (1997) showed that climate response is approximately proportional to forcing at specific latitudes, regardless of the nature of the forcing. Shindell and Faluvegi (2009) apportioned temperature responses in the Arctic to forcing within specific latitude bands. Koch et al. (2007) calculated forcing both attributed to specific regions and acting upon specific regions. Here, we provide a formal framework to quantify this spatial nonuniformity as it relates to both emission and receptor regions.

\subsection{Definition of the Specific Forcing Pulse}

We define the Specific Forcing Pulse $\mathrm{SFP}_{E}^{S}$ as the energy added to the Earth-atmosphere system by one gram of species $S$ emitted in region $E$, during its entire lifetime. We further define the SFP for energy added within a region, $\operatorname{SFP}_{E}^{S}\left(R_{j}\right)$, as the energy added to a region $R_{j}$ by one gram of $S$ emitted in region $E$. The units of SFP are joules per gram emitted. SFP provides a policy-relevant measure: ben- efit, or disbenefit, per mass emitted - the "bang for the buck." The formal equation is:

$$
\begin{aligned}
\operatorname{SFP}_{E}^{S}\left(R_{j}\right)= & \frac{1}{M_{E, 0}^{S}} \int_{\varphi 1}^{\varphi 2} \int_{\theta 1}^{\theta 2} \int_{t=0}^{1 y r} f_{E}^{S}(\theta, \varphi, t) b_{E}^{S}(\theta, \varphi, t) \\
& \rho_{\text {earth }}^{2} \cos \theta d \theta d \varphi d t
\end{aligned}
$$

where $f_{E}^{S}$ is the net change in the rate of energy input per mass of $S$ in the system $\left(\mathrm{W} \mathrm{g}^{-1}\right) ; b_{E}^{S}$ is the column burden or surface loading $\left(\mathrm{g} \mathrm{m}^{-2}\right)$ of the substance at $(\theta, \varphi)$ remaining at time $t$ from an emission pulse of magnitude $M_{E, 0}(\mathrm{~g})$ in region $E, \varphi_{1}$ and $\varphi_{1}$ are the longitude boundaries of $R, \theta_{1}$ and $\theta_{2}$ are the latitude boundaries of $R$, and $\rho_{\text {earth }}$ is the radius of the Earth. The subscript $E$ is included for $f$ and $b$ because the characteristics of species $S$ within region $R$ may differ with emitting region. The upper integral limit of one year comes from our definition of immediacy in the previous section.

Figure 2 demonstrates the integral of forcing by black carbon emissions from a particular region over a receptor region of interest. The maps on the left show direct radiative forcing per emission from two regions, and the panels to the 

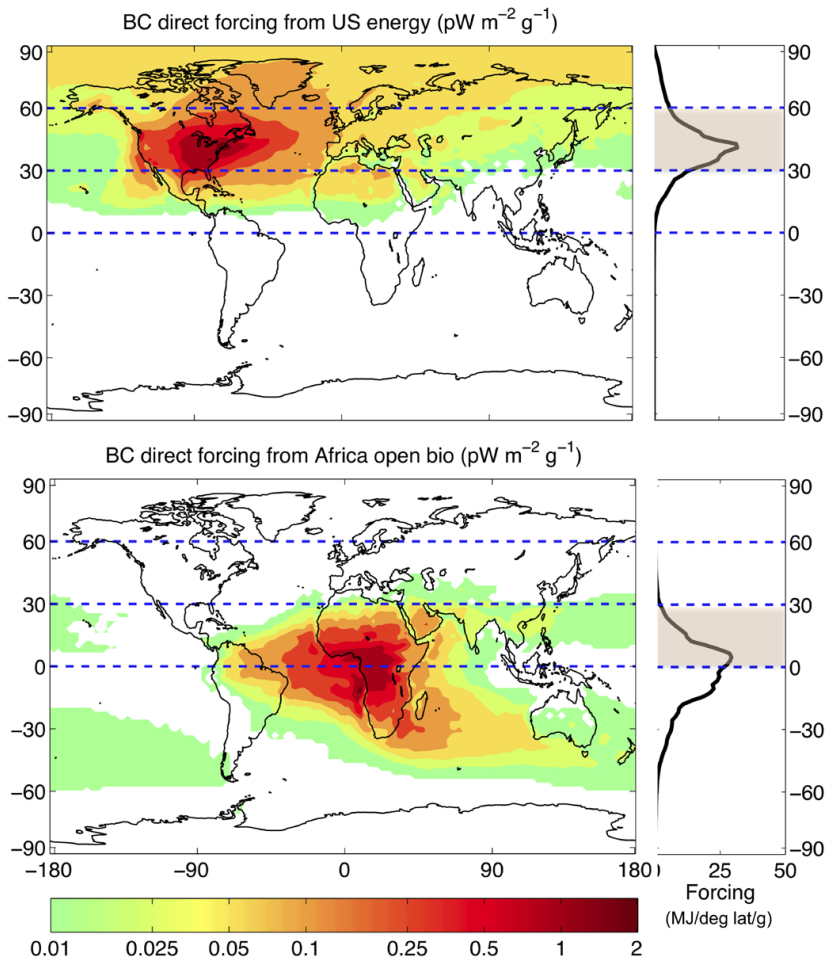

Fig. 2. Demonstration of forcing by $\mathrm{BC}$ emitted in a specific region, exerted upon other receptor regions. Here, the receptor regions are latitude bands. Maps to the left show total forcing from energyrelated emissions in the United States (top) and open biomass burning in Africa (bottom). Figures to the right show zonal integrals of forcing, normalized to emissions. SFP is the integral over latitudes of interest. Shading in the right graphs shows two examples: $S F P_{\mathrm{USen}}^{\mathrm{BC}}\left(30^{\circ}-60^{\circ} \mathrm{N}\right)$ and $S F P_{\text {AfrOpen }}^{\mathrm{BC}}\left(0^{\circ}-30^{\circ} \mathrm{N}\right)$.

right show zonal integrals of the forcing, normalized by total regional emissions. There are marked differences in the latitudinal dependence of forcing by emissions from each region. Two examples of SFP calculation are marked in the figure: $\operatorname{SFP}_{\mathrm{USen}}^{\mathrm{BC}}\left(30^{\circ}-60^{\circ} \mathrm{N}\right)$ and $\operatorname{SFP}_{\mathrm{AfrOpen}}^{\mathrm{BC}}\left(0^{\circ}-30^{\circ} \mathrm{N}\right)$. This forcing assumes present-day spatial distribution of emission.

We propose that energy (joules) added to a specific region, rather than power (watts, energy per time) or radiative forcing (watts per area), is a basic measure for forcings that begin and end rapidly. While other impacts are best quantified in terms of forcing integrated over time, with units of $\mathrm{W} y r$, units of J indicate that SLCF forcings are fundamentally different. They are better represented as delta functions, characterized by an area under a curve rather than the curve's height or width. For a true delta function, the integral is identical for any upper limit of the time integral, ranging from a small time step to infinity. The term "pulse" may also be used when any reasonable choice of the integral limit yields an identical result, as it does for SLCFs.
The pulse representation is limited to climate forcers with relatively short lifetimes. For $\mathrm{CO}_{2}$, integrated forcing during the first year after emission is less than $2 \%$ of the integrated forcing over 100 years, so this forcing does not occur as a pulse. While SFP is appropriate for short-lived species, the effects of longer-lived species should be described as integrated forcing. Impacts of species that act on both short-lived and long-lived components, such as carbon monoxide acting on ozone and methane, might be partitioned into two components: a pulse and an integrated forcing.

By convention, the term "forcing" is usually defined with regard to the net perturbation at the top of the atmosphere (TOA). We will present TOA values here unless otherwise stated, but we will also show that the concept of SFP can be used to communicate other changes in energy balance (see Sect. 3.3).

\subsection{Connection between SFP and modeled forcing}

Although global chemical-transport models usually do not use pulse emission functions, SFP can be determined from their output, with some limitations. An explanation that uses a first-order box model is given in Appendix A (Supplement). Annually-averaged values of SFP can be determined from models with constant emission rates as the ratio of forcing to emission, with a change in units. This calculation is possible only for short-lived species, for which burdens are in equilibrium with emissions.

The box-model derivation also shows that SFP is the product of forcing per mass $\left(f^{S}\right)$ and lifetime $\left(\tau^{S}\right)$. These two values can aid in diagnosing reasons for differences in SFP among seasons or regions.

\subsection{Connection between SFP and global warming potentials}

In this paper, we present SFP to quantify forcing that depends on the regions of emission and of forcing. Such quantification may lead to a better understanding of the benefits (or costs) of reducing SLCF emissions. We do not propose SFP as a trading metric here, as it captures impacts that cannot be reflected in globally-averaged, integrated metrics. However, many discussions about mitigating climate-active species require trading metrics such as Global Warming Potentials (GWPs). Because of this history, we draw connections between SFP and more traditional measures such as GWP.

\subsubsection{Absolute global warming potential}

The absolute global warming potential (AGWP), has the same basic calculation as the SFP, integrating forcing over the time since emission. This value, multiplied by annual emissions, was demonstrated by Forster et al. (2007). The 
units of AGWP are $\mathrm{W} \mathrm{m}^{-2} \mathrm{yrg}^{-1}$. Its definition can be written:

$\operatorname{AGWP}^{S}(H) \frac{1}{M_{0}^{S}} \int_{0}^{H} f^{s} b^{s}(t) d t$

where $H$ is a chosen time horizon and all other variables are as in Eq. (1). SFP has some important differences from AGWP, and we propose it to provide quantification that AGWP cannot.

Regionality. SFP refers to forcing within a specific region, not a global average. However, the global sum of SFP (with a change in units) equates to AGWP. For such regional energy flows, SFP must have either units of power (W) or energy (J) instead of forcing units $\left(\mathrm{W} \mathrm{m}^{-2}\right)$, because the latter are not conservative. Fasullo and Trenberth (2008) use watts for regional energy flows in an energy-balance model; we choose joules to express the integral nature of the pulse.

Timing of forcing. When a value is presented as SFP, it is clear that the forcing occurs immediately, by our definition of the word.

Representativeness of steady state. SFP can be multiplied by emission rate to obtain annual forcing, while the same is not true of AGWP for longer-lived pollutants.

Independence of time horizon. We limit the use of SFP to forcings that are effectively pulses, so that a one-year time integral captures $95 \%$ of the forcing for short-lived species. Although the upper limit of the time integral in Eq. (1) is one year, the same answer would result from any longer value of the time horizon. This means that SFP does not depend on the value of $H$ for any reasonable choice. In contrast, the value of AGWP remains ambiguous until $H$ is chosen. That is,

$\frac{1}{A_{\text {earth }}} \sum_{j} \operatorname{SFP}^{s}\left(R_{j}\right)=\operatorname{AGWP}^{s}(H)$

for any value of $H$.

We have also chosen some different terminology. We avoid the term "global warming" because SFP is neither global nor required to produce warming. We identify the SFP as a "pulse" rather than a "potential" because it is not referenced to a chosen substance, as are global warming potentials and ozone depletion potentials. Finally, we choose the term "specific" to have the same meaning as in "specific heat": the sense of forcing per mass. The term is included as a reminder that the determination of total forcing for SLCFs is inseparable from emission rate.

\subsubsection{Global warming potential}

The currency of climate mitigation discussions is presently "carbon equivalence" using the global warming potential (GWP), which is defined as:

$\operatorname{GWP}^{s}(H)=\frac{\int_{0}^{H} f^{s} m^{s}(t) d t}{\int_{0}^{H} f^{\mathrm{CO}_{2}} \mathrm{CO}^{2}(t) d t}$
The denominator gives the amount of forcing by $\mathrm{CO}_{2}$ during the time horizon $H$, and the numerator is both the AGWP and the global sum of regional SFPs, so that

$\operatorname{GWP}^{s}(H)=\frac{\operatorname{AGWP}^{s}(H)}{\operatorname{AGWPCO}_{2}(H)}=\frac{\sum_{j} \operatorname{SFP}^{s}\left(R_{j}\right)}{\text { Aearth } \cdot \operatorname{AGWP}^{C_{2}}(H)}$

The choice of $H$ reflects the value of future climate benefits, and the time horizon amounts to a value judgment about the importance of future forcing. Current negotiations use $H=100$ years, but others (e.g. 20 or 500 years) are also discussed. The choice of $H$ matters only when some pollutant remains in the atmosphere at the end of the time period, as is the case for $\mathrm{CO}_{2}$ but not for SLCFs. Vast differences in GWP for $H=20$ years versus $H=100$ years (Fuglestvedt et al., 2009) result entirely from the denominators in Eqs. (4) and (5). The use of SFP as opposed to AGWP clarifies that forcing occurs immediately and that it is all counted. SFP conveys purely physical information about forcing. It has a direct connection to policy-relevant metrics, yet it requires no choices that favor particular policies or value judgments.

A value of GWP can be obtained by dividing global SFP by a selected value for $\mathrm{CO}_{2}$ integrated forcing. Using the Bern carbon model to represent life cycle, $a_{\mathrm{CO} 2}$ from IPCC's Fourth Assessment Report (chp 2), and a zero discount rate for future forcing, the value of the denominator in Eq. (5) is $1.4 \times 10^{-3} \mathrm{GJ} \mathrm{g}^{-1}$ for $\tau=100$ years, and $4.0 \times 10^{-4} \mathrm{GJ} \mathrm{g}^{-1}$ for $\tau=20$ years.

\subsection{Application of SFP to temperature change calculations}

A primary use of SFP is connecting decisions regarding mitigation and future emission in particular regions with the resulting climate forcing. The units of SFP are energy added to the Earth system per emission: joules per gram. This fundamental quantity can be used directly in energy-balance approaches to the Earth system (e.g. Murphy et al., 2009). Because it represents forcing per emission, SFP can also be used to estimate immediate forcing reductions caused by mitigating black carbon or ozone, or decreased negative forcing ("unmasking") due to sulfur controls. Integrated assessment models (Alcamo et al., 1994; Smith et al., 2000) can use SFP to connect predictions of SLCF emission with radiative forcing and climate response.

However, it is important to remember that forcing and warming are not the same. Forcing is an input to the Earth system and does not account for its response (i.e., feedbacks). SFP cannot be divided by the Earth's heat capacity to determine temperature change. Instantaneous forcing on a system that is not in equilibrium cannot be divided by climate sensitivity to determine temperature change, either.

Also importantly, forcing in a particular region is not proportional to temperature change in that region. Forcing and temperature change within a region may even have opposite 
signs. Shindell and Faluvegi (2009) showed that Arctic temperature response depended on the forcing latitude, but in a non-intuitive way. In Appendix B, we propose a method to account for the regional dependence of SFP in simple climate models. This derivation there is presented to foreshadow the need for regional SFP, a discussion that will occupy Sect. 3 and onward. Readers who expect to perform simple temperature change calculations using SFP should consult Appendix B.

\section{Single-model, regional estimates of SFP}

In this section, we present values of the Specific Forcing Pulse for black carbon (BC) and organic matter (OM) particles emitted from different regions, obtained from a single model. The idea of representing immediate changes in forcing could be used to communicate many changes in the radiative balance: warming or cooling of the atmosphere due to direct interaction with sunlight (dir); albedo changes in the cryosphere (snow and ice, cry); changes in warm clouds, and changes in cold or mixed clouds. We quantify only direct and

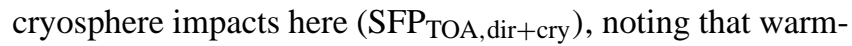
cloud and cold-cloud changes could greatly alter the estimate of impact.

\subsection{Model description}

We used the Community Atmosphere Model (CAM, Collins et al., 2006), developed at the National Center for Atmospheric Research, to model atmospheric and cryospheric (snow and ice) forcing by black and organic carbon. Figure 3 shows total forcing by $\mathrm{BC}$ and organic matter in the atmosphere, and by $\mathrm{BC}$ on snow and ice. Atmospheric temperature and pressure were prescribed from NCEP reanalysis data, strongly constraining model winds. Energyrelated emissions, from year 2000 in Bond et al. (2007), were $4400 \mathrm{Gg} \mathrm{yr}^{-1}$ and $8900 \mathrm{Gg} \mathrm{yr}^{-1}$ for black and organic carbon, respectively. Open-burning emissions from the Global Fire Emission Database, version 2 (van der Werf et al., 2006) averaged $2600 \mathrm{Gg} \mathrm{yr}^{-1}$ and $21000 \mathrm{Gg} \mathrm{yr}^{-1}$ and included seasonality during each model year. The primary purpose of this model run is to produce values of forcing per emission, so the total values of emission are less important. Agricultural burning was not included because it appears in neither emission database.

Aerosol optics were modified to reflect recent recommendations for black carbon (Bond and Bergstrom, 2006; Bond et al., 2006), including "coating" or internal mixing. This version of CAM does not have a full aerosol microphysical model, but the effects of coating can be approximated with higher absorption for black carbon particles that have aged. In our model, this transition has a characteristic time of about 1.2 days. The organic matter in CAM has minimal absorption, ignoring the contribution of "brown" carbon, which has
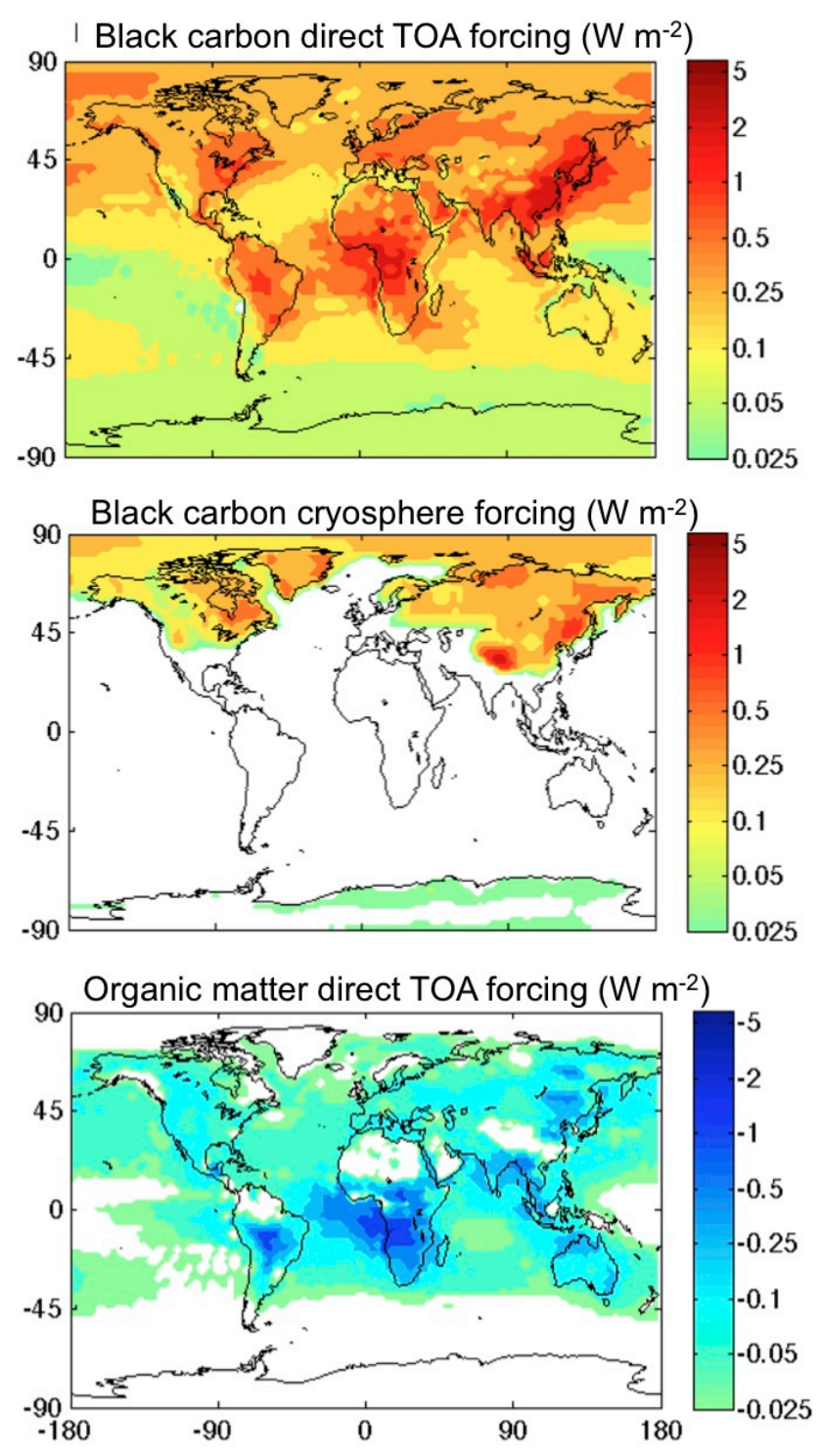

Fig. 3. Forcing by black carbon in atmosphere and on snow, and by organic matter, simulated with the Community Atmosphere Model.

a small amount of absorption. Organic matter is less hygroscopic than sulfate, and therefore scatters less per mass. Model results are averaged over five years, after a discarded spin-up period of 4 months. This model produces globalaverage atmospheric forcing by black carbon from fossil fuels, biofuels, and open burning of $+0.40 \mathrm{~W} \mathrm{~m}^{-2}$, and globalaverage forcing by organic matter of $-0.12 \mathrm{~W} \mathrm{~m}^{-2}$. No natural background is subtracted from those forcing values. Forcing is determined as the difference between two model runs in which aerosol forcing is not allowed to interact with the climate system. Thus, the values presented here exclude any fast responses or climate responses. 


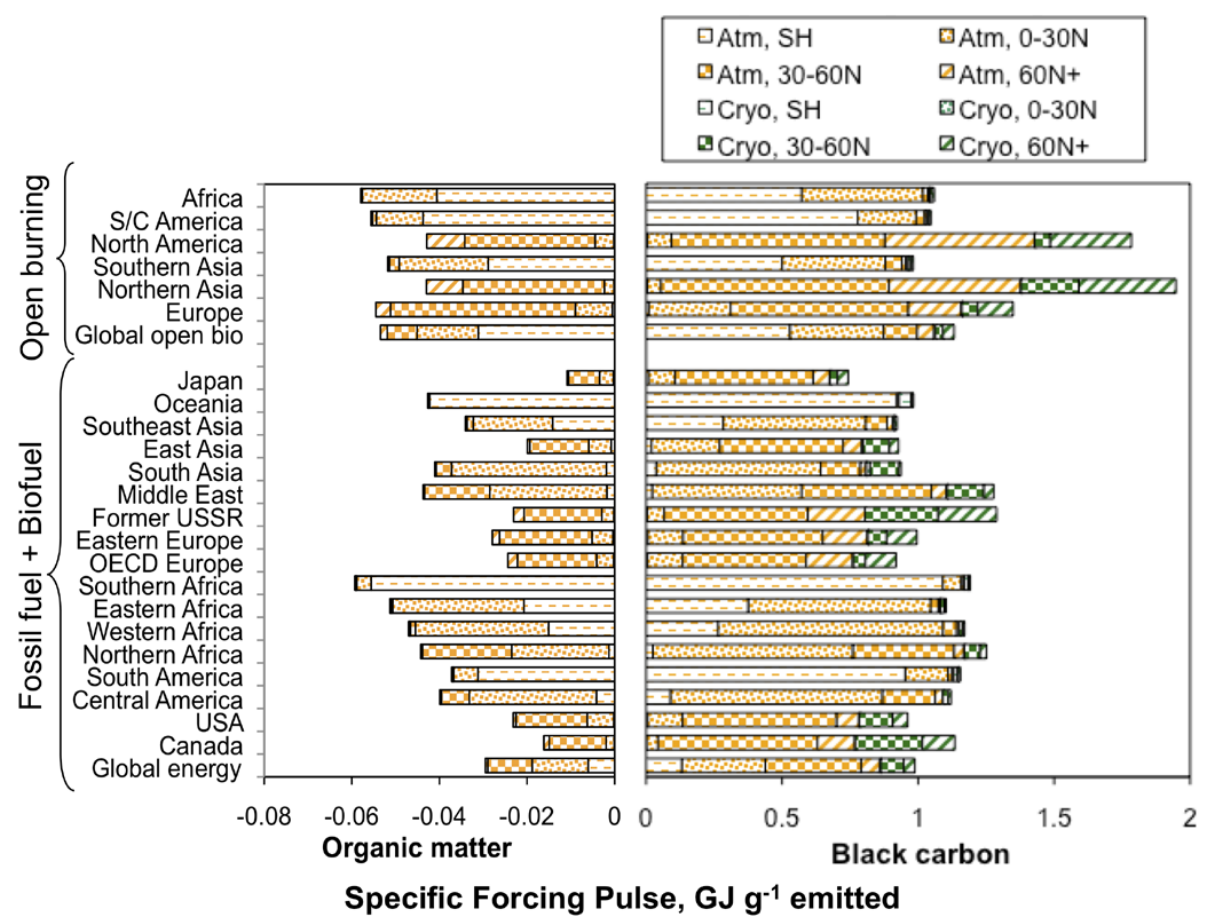

Fig. 4. Specific Forcing Pulse for BC and OM aerosol emitted from 23 region-source combinations, estimated with a single model (NCAR CCSM). SFP includes direct atmospheric and cryosphere impacts only. Note the difference in scale between the positive values for black carbon and negative values for organic matter. The single-model values presented in this figure are adjusted to reflect model ensembles in Table 1 .

Emissions from 23 separate region and source combinations (17 energy and 6 open burning) were tagged so that concentrations and deposition at each location could be attributed to source regions. The 17 regions reflect the groupings in a common integrated assessment model (IMAGE, Alcamo et al., 1994). We apportioned forcing in each model grid box $\left(1.9^{\circ} \times 2.5^{\circ}\right)$ to the column burden of the aerosol from each region. Forcing through changes in ice and snow albedo was also modeled in a separate twenty-year equilibrium run (Flanner et al., 2009, run PD1). We apportioned this forcing to the 23 emitting regions using deposition of the tagged tracers. Global-average cryosphere forcing is $+0.047 \mathrm{~W} \mathrm{~m}^{-2}$, with $20 \%$ of the total occurring in the Arctic $\left(60^{\circ}\right.$ to $\left.90^{\circ} \mathrm{N}\right)$.

\subsection{Regional estimates of SFP for black and organic matter}

Figure 4 shows $\mathrm{SFP}_{\mathrm{TOA}, \text { dir+cry }}$ for black carbon and organic matter emitted from each 23 region-sector combination. The magnitude of each bar indicates the global SFP, or the total energy added to the global atmosphere and cryosphere by one gram of emissions from that region. SFP for each region is also divided among the latitudes where forcing occurs, as demonstrated in Fig. 2. The apportionment of SFP into forcing regions is less certain than the global sum of SFP, because zonal transport is not well constrained and varies among models (Textor et al., 2006), Unsurprisingly, dominant impacts are found at the same latitude as the region of emission.

$\mathrm{BC}$ has positive global SFP (warming), while the negative global SFP shows the cooling effect of reflective OM. There is more than an order of magnitude difference between the cooling per mass of $\mathrm{OM}$ and the warming per mass of $\mathrm{BC}$; the latter is far more effective at interacting with visible radiation. For energy-related emissions, global SFP of BC and $\mathrm{OM}$ averages +0.99 and $-0.030 \mathrm{GJ} \mathrm{g}^{-1}$, respectively. Emissions from open burning have higher $\mathrm{SFP}_{\mathrm{TOA}}$ : +1.13 and $-0.053 \mathrm{GJ} \mathrm{g}^{-1}$ for $\mathrm{BC}$ and $\mathrm{OM}$, respectively. Averages for all emissions are $+1.05 \mathrm{GJ} \mathrm{g}^{-1}$ for $\mathrm{BC}$ and $-0.037 \mathrm{GJ} \mathrm{g}^{-1}$ for OM.

The orange portion of each bar shows direct TOA forcing at different latitudes. These are the integrals over the latitude bands indicated in Fig. 2. For example, the diagonally hatched portion of each bar represents energy added to the atmosphere within the Arctic (latitude $60-90^{\circ} \mathrm{N}$ ). Energy added by cryosphere forcing is also shown as green bars. Cryosphere forcing is effective at inducing changes in snow and ice cover, a feedback that causes a higher temperature change per forcing for snow darkening than for $\mathrm{CO}_{2}$ (Hansen and Nazarenko, 2004; Flanner et al., 2007). This fast response would yield a high efficacy, but is not included here. 


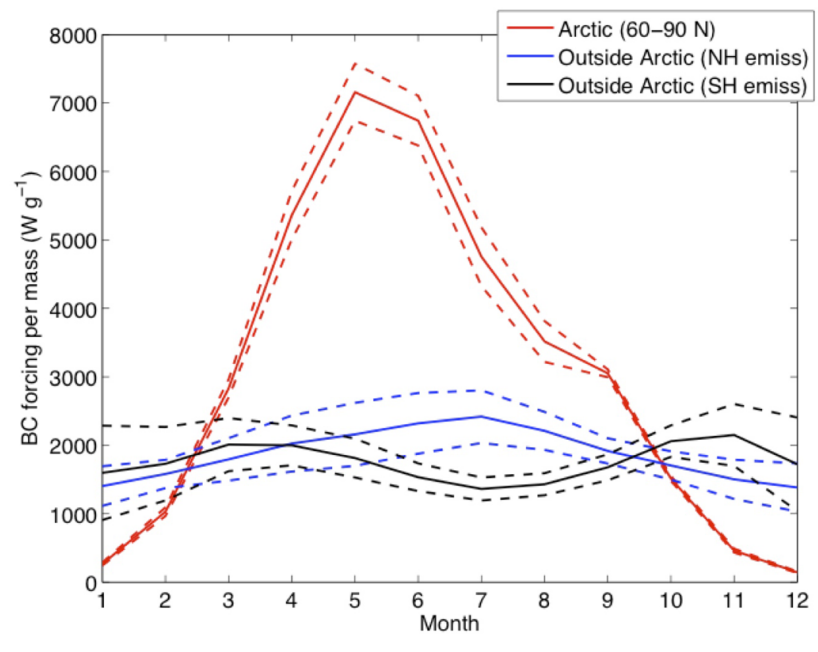

Fig. 5. Forcing-per-mass $\left(f^{S}\right)$ for black carbon in each month. Solid lines are global averages; dashed lines represent one standard deviation of the plotted regions. Arctic group (red) contains 23 regions and represents aerosol transported to the Arctic from all 23 regions. Other groups represent forcing-per-mass of all aerosol emitted from each region not located in the Arctic. NH outside Arctic (blue) contains 18 regions; SH outside Arctic (black) contains 5 regions.

$\mathrm{BC}$ reduction of snow albedo $\left(\mathrm{SFP}_{\text {cry }}\right)$ increases $\mathrm{SFP}_{\mathrm{TOA}}$ by about $15 \%$ on a global average. This contribution is important for, but not confined to, emissions in northern regions: Europe, the former USSR, and North America. Despite this cryosphere-forcing contribution, SFP in these regions is similar to that in more southerly regions. Cooler regions are closer to snow, but these regions have less deep convection and the aerosol has shorter atmospheric lifetimes. The variation of SFP among regions, and the difference between energy-related and open-burning SFP, is caused by seasonal and environmental differences in forcing per mass $(f)$ and aerosol lifetime $(\tau)$. SFP is the product of these two factors. Figure 5 shows the seasonality of $f^{\mathrm{BC}}$. For $\mathrm{BC}$ outside the Arctic, $f^{\mathrm{BC}}$ varies by $10-40 \%$ throughout the year depending on the emitting region. Average $f^{\mathrm{BC}}$ for extra-Arctic BC is about $40 \%$ higher in summer because the aerosol absorbs more sunlight during longer days. It also increases in summer because deep convection lofts the BC above reflective clouds, causing longer $\tau$ and greater $f^{\mathrm{BC}}$. (BC over a reflective surface has higher forcing per mass.) This seasonality explains the higher $\mathrm{SFP}^{\mathrm{BC}}$ for open burning emissions compared with energy-related emissions, as the former emit preferentially during summer.

For BC within the Arctic, warming per mass is strongly seasonal. Large variations are caused much more by the availability of sunlight in the Arctic than by emitting region. Very little OM cooling occurs in the Arctic, because reflective OM over a bright surface has little effect on the radiative balance.
Even when emissions are constant in time, as they are for energy-related emissions, global SFP depends on the region of emission. There is a $45 \%$ difference among global SFP ${ }^{\mathrm{BC}}$, and a factor of 4 difference among global SFPOC for energyrelated emissions. The diversity would be greater if Japan were included. Emissions from this island nation have a much lower SFP because of their environment, but we neglect it in considering diversity because the emissions are small.

\subsection{Vertical energy distribution}

In this paper, we mainly discuss how the addition or reduction of energy by aerosols is distributed horizontally across the Earth's surface. SFP can also represent changes in energy balance in the vertical direction caused by BC absorption. OM has little impact on atmospheric heating, unless it absorbs light, and it is not discussed here.

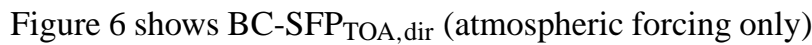
for the 23 regions, this time showing the division between atmospheric heating ( $\mathrm{SFP}_{\text {heating }}$ ) and negative forcing at the surface $\left(\mathrm{SFP}_{\text {surf }}\right)$. Top-of-atmosphere forcing is the sum of

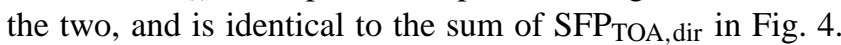
The diversity of $\mathrm{SFP}_{\text {heating }}$ among regions is similar to that of $\mathrm{SFP}_{\mathrm{TOA}, \mathrm{dir}}$, and biomass-burning $\mathrm{BC}$ again has a stronger impact per emission. Figure 6 demonstrates how BC affects energy redistribution. Each gram of emitted BC adds about $1 \mathrm{GJ}$ to the Earth-atmosphere system, but that energy is distributed as $2.4 \mathrm{GJ}$ of increased atmospheric absorption, counteracted by $1.5 \mathrm{GJ}$ that does not reach the surface. As the surface energy budget is relevant to determining changes in the hydrologic cycle (Chung et al., 2002; Meehl et al., 2008), $\mathrm{SFP}_{\text {surf }}$ may also be useful for simple models.

\section{Ensemble adjustments to reflect model diversity}

In the previous section, we used a single model (CAM) to produce estimates of SFP for emissions from particular regions. Single-model estimates are insufficient because inputs and model parameterizations are uncertain. Values that reflect a multi-model "consensus" would be preferable. However, we face a challenge: no other model has estimated forcing for 23 regions, and few incorporate the representation of internal mixing that enhances absorption by $\mathrm{BC}$.

Rather than discarding model results that lack sufficient detail for our purposes, we suggest that diversity among models is still a useful representation of uncertainty when the causes of variation are treated as explicitly as possible. Our goal is to provide best estimates and uncertainties for SFP that retains the features of our CAM estimate, including regionally-specific forcing, but that also captures diversity represented by other models.

In this section, we use the CAM results along with those of 12 other models, most of which are summarized by Schulz 


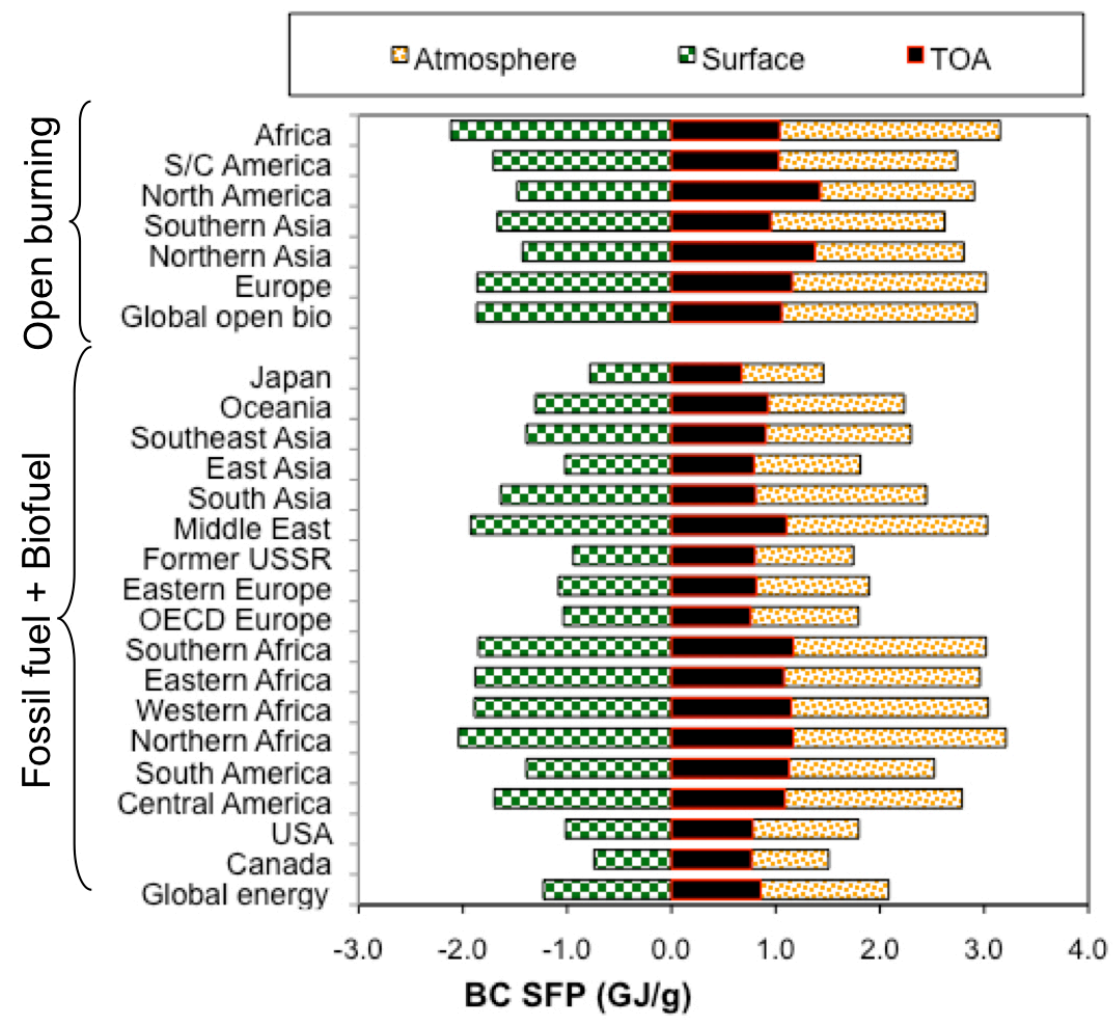

Fig. 6. SFP for black carbon, showing impact on vertical energy balance. Energy is added to atmosphere (orange bars, positive SFP) and removed from surface (green bars, negative SFP). Top of atmosphere value (black bars) is net of surface and atmosphere and is comparable to Fig. 2 .

et al. (2006), to provide best estimates and uncertainties for SFP. Because most models produce only global totals for SFP, we will discuss those before developing regional estimates. We first outline the general approach to developing estimates from an ensemble of models (Sect. 4.1), and then describe variability in global SFP indicated by the model ensemble (Sect. 4.2). In later sub-sections, we address how aerosol mixing (Sect. 4.3), regionality (Sect. 4.4), and poleward transport (Sect. 4.5) affect our estimates of SFP.

\subsection{General approach to simple ensemble adjustments}

We separate model diversity into two categories: identified and baseline. Identified diversity can be attributed to a distinct factor that varies between models, such as inclusion of a process or a change in aerosol optical properties. Baseline diversity includes the remainder of the model diversity and its causes remain unknown without further investigation. The separate treatment of individual factors is desirable when model representations are known to be biased and could be corrected, or when there is interest in exploring whether models agree on a particular effect. If a factor causes important changes in forcing, it should be isolated so observational studies can be designed to diagnose it.
We define a baseline simulation as one in which the factors of interest have similar assumptions for all models. The notion of a common baseline treatment is quite plausible, as many aerosol models use similar parameterizations of removal, or optical properties. Next, we define enhancement predicted by model $m\left(E_{m}\right)$ due to an identified factor (fact) as the ratio of SFP values determined from two separate simulations, one with the model's own treatment of the factor, and one with the baseline treatment:

$E_{m, \text { fact }}=\left(\mathrm{SFP}_{m} / \mathrm{SFP}_{m, \text { base }}\right)$

SFP for all factors predicted by model $m$ is then

$\mathrm{SFP}_{m, \text { full }}=\mathrm{SFP}_{m, \text { base }} \prod_{n} E_{m, \text { fact } \# n}$

This equation assumes that the identified factors have multiplicative effects on forcing, which is true if they affect normalized forcing or lifetime. We also assume that factors are independent. If they are not, then correlations must be considered.

SFP for any model has the following relationship with SFP from a reference model. This relationship defines 
the baseline adjustment $\left(\mathrm{A}_{m}\right.$,base $)$ and the factor adjustment $\left(A_{m, \text { fact\#n }}\right)$ suggested by model $m$.

$$
\begin{aligned}
\operatorname{SFP}_{m, \text { full }} & =\mathrm{SFP}_{\text {ref,full }} \frac{\mathrm{SFP}_{m, \text { base }}}{\mathrm{SFP}_{\text {ref, base }}} \prod_{n} \frac{E_{m} \mathrm{fact \# n}}{E_{\text {ref,fact\#n }}} \\
& =\mathrm{SFP}_{\text {ref,full }} A_{m, \text { base }} \prod_{n} A_{m, \text { fact\#n }}
\end{aligned}
$$

The adjustments, $A$, are the values by which the reference model's baseline $\left(\mathrm{SFP}_{\text {ref,full }}\right)$ or enhancement $\left(E_{\text {ref,fact\#n }}\right)$ would have to be multiplied to reproduce values given by model $m$.

Our goal is to combine as much information as possible from the ensemble of models to obtain a best estimate and uncertainty for SFP. However, we should also discount model results that are less realistic. If a model does not treat a factor appropriately or cannot represent it, the value of $A_{m}$,fact\#n for that model will be disregarded or given a lower weight. Even if a model does not represent all the desired factors properly, it can still provide a value of $A_{m}$,base, as well as other $A_{m, \text { fact\#n }}$.

Finally, the best guess of SFP including uncertainty is:

$$
\mathrm{SFP}_{\text {best }}=\mathrm{SFP}_{\text {ref,full }} A_{\text {ens, base }} \prod_{n} A_{\text {ens,fact\#n }}
$$

In Eq. (11), the ensemble baseline adjustment ( $\left.A_{\text {ens, base }}\right)$ is determined by examining all values of $A_{m}$,base to produce a central value and uncertainty. If a large number of models contributes to the estimate, $A_{\text {ens, base }}$ may be the mean or median value, and the uncertainty could be given by the standard deviation or interquartile range. Variation in the baseline adjustment expresses diversity in model formulations that are not captured in any factor adjustment.

Each ensemble factor adjustment $\left(A_{\text {ens,fact\#n }}\right)$ is developed by examining all available values of $E_{m \text {, proc\#n }}$. These values may be provided by only a subset of the models. If model $m$ predicts the same enhancement as the reference model (i.e. $\left.E_{\text {ref, fact\#n }}=E_{m, \text { fact\#n }}\right)$, then $A_{m, \text { fact\#n }}=1$. Because of large differences in implementation within each model, it is difficult to give rigid rules for choosing values for $A_{\text {ens, proc. }}$ Section 4.2 contains the simplest demonstration of this procedure.

Our proposed framework provides a more rigorous estimate than does simply averaging the 13 model values of SFP, because it identifies the sources of uncertainty. Division of modeled forcing into components is not a new idea; it was explored by Schulz et al. (2006) and Textor et al. (2006). However, this idea has not yet been carried forward to communicate forcing per emission. It is possible that this framework could overestimate the uncertainty in SFP, as models may contain compensating errors that allow them to match measurements. However, if modeled concentrations from each model are broadly consistent with observations, the diversity in modeled emissions, aerosol lifetimes and forcing-per- mass represents true variability in plausible values for these parameters.

In the sections that follow, we use the values of SFP determined in Sect. 3 as $\mathrm{SFP}_{\text {ref. }}$. We first discuss the ensemble adjustment $A_{\text {base }}$ (Sect. 4.2). Sect. 4.3 discusses mixing between black carbon and non-absorbing aerosol components. This process increases absorption and positive forcing, yet many models do not represent it. We also discuss variability among regions (Sect. 4.4) and Arctic transport (Sect. 4.5) to investigate whether models agree on regional variability. Other model factors could be explored in this framework. For example, the hygroscopicity of organic matter affects direct radiative forcing. However, no results from fully-sensitive models are available to provide values of the enhancement, so variability resulting from this treatment remains in the model uncertainty.

\subsection{Ensemble baseline adjustment, $A_{\text {base }}$}

The group of models that will be discussed here has mostly been tabulated by Schulz et al. (2006) for the AeroCom initiative. This tabulation also includes results of models that did not participate in AeroCom. Models without internal mixing form the baseline ensemble. We discarded values that were later superceded by the same research group, reasoning that if the individual researchers have moved beyond their early estimates, the community should too. We also eliminate one model that included only clear-sky forcing (Schulz et al., 2006).

For BC forcing, the baseline ensemble includes models E, H, I, and L-S from Schulz et al. (2006), from Jones et al., 2007, (HadGEM1, $+0.39 \mathrm{~W} \mathrm{~m}^{-2}$ or $+86 \mathrm{GJ} \mathrm{g}^{-1}$ ), and our CAM run with no internal mixing $\left(+0.57 \mathrm{GJ} \mathrm{g}^{-1}\right)$. Two models may have chosen relatively high mass absorption crosssections for BC (UIO-GCM and SPRINTARS) in an attempt to acknowledge absorption increase due to internal mixing. These were adjusted downward by the ratio between the absorption cross-section for unmixed BC $\left(7.5 \mathrm{~m}^{2} \mathrm{~g}^{-1}\right.$, Bond and Bergstrom, 2006) and the value used in the model to achieve a baseline value.

Figure 7 shows the cumulative distribution of modeled SFP for the 13 models. The figure also shows the value of $A_{\text {base}}$, or each model's SFP divided by our reference value of $+0.57 \mathrm{GJ} \mathrm{g}^{-1}$. The mean and median for $\mathrm{SFP}^{\mathrm{BC}}$ are almost identical $\left(0.61 \mathrm{GJ} \mathrm{g}^{-1}\right.$ and $0.62 \mathrm{Gg}^{-1}$, respectively). The value of $A_{\text {ens, base }}$, using the median as the best guess and the 10 -th and 95 -th percentiles, is $1.06 \pm 0.34$. By choosing this value, we set the best guess of baseline SFP to the median of the baseline ensemble.

Jones et al. (2007) do not give a forcing estimate for OM. For the remaining 12 models, the mean and median SFPOM are -0.052 and $-0.049 \mathrm{GJ} \mathrm{g}^{-1}$, respectively. Our baseline value $\left(-0.038 \mathrm{GJ} \mathrm{g}^{-1}\right)$ is lower in magnitude than the ensemble median, and $A_{\text {ens, base }}$ is 1.30 , again using the median. The 10-th and 90-th percentiles give an $A_{\text {ens, base }}$ range 


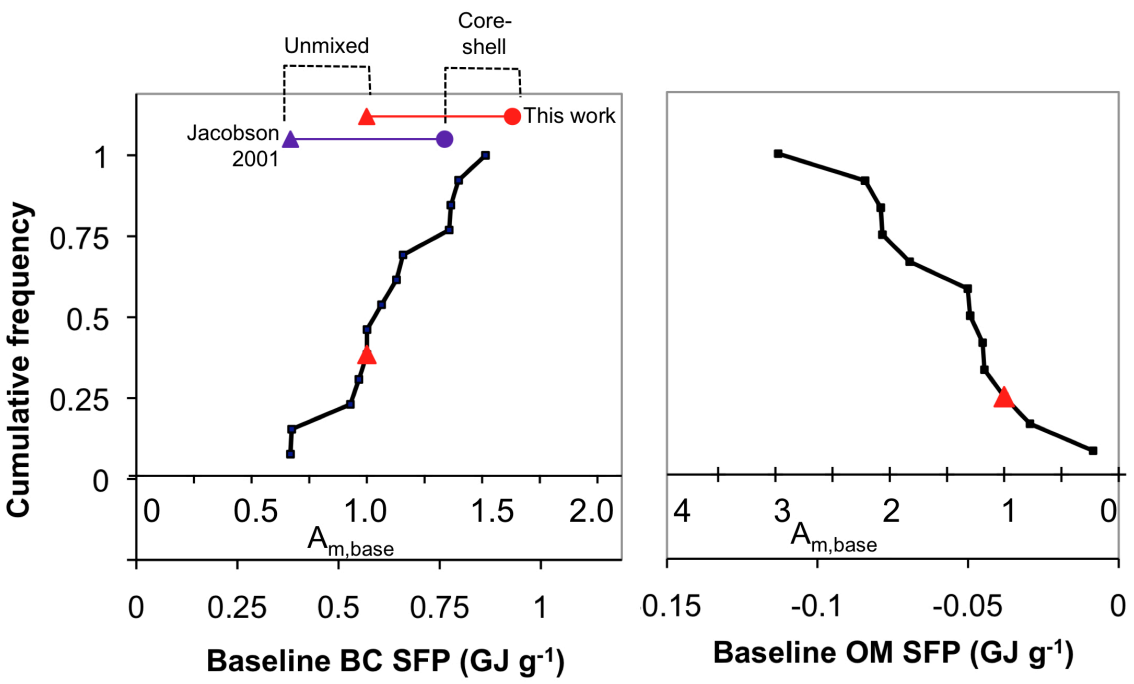

Fig. 7. Comparison of our baseline model results with AeroCom tabulation. Each figure shows $\mathrm{SFP}_{\text {dir }}$ derived from 12 models in the AeroCom tabulation, which reported normalized direct radiative forcing and aerosol lifetime. Cumulative graphs indicate the fraction of models reporting $\mathrm{SFP}_{\text {dir }}$ below the indicated value. $A_{m}$, base is the SFP for each model divided by SFP for the reference model (red triangle). Figure for black carbon (left) also shows the effect of internal mixing from CAM and one other model (top). Ratio between core-shell SFP and unmixed SFP indicates enhancement $\left(E_{\text {mix }}\right)$.

of $(0.8,2.2)$; the adjustment is not symmetric. There is a factor of 13 difference between maximum and minimum, compared with a factor of two for BC. This greater disparity for OM may reflect a wider range of choices among the water uptake and light absorption properties that affect forcing.

\subsection{Black carbon mixing: $E_{\text {mix }}$ and $A_{\text {mix }}$}

Mixing of black carbon with other aerosol components within individual particles ("internal mixing") increases absorption, and hence positive forcing, as first suggested by Ackerman and Toon (1981). This increase in absorption is not controversial. It has been confirmed in laboratory measurements (Schnaiter et al., 2005) and mixing occurs quickly after emission (Shiraiwa et al., 2007). This enhancement by mixing is already included in $\mathrm{SFP}_{\text {ref,full }}$, but it is missing from many published model results. This situation is being rectified as aerosol models advance, but a full suite of upgraded model results is not yet available. We examine only atmospheric forcing to determine $E_{\text {mix }}$ and $A_{\text {mix }}$. To the best of our knowledge, our discussion here covers all published model reports from which enhancements could be derived. Kopp and Mauzerall (2010) also adjusted globallyaveraged forcing for models that did not represent internal mixing. Here, we formalize this type of analysis.

CAM simulations without and with mixed aerosol gave SFP of +0.57 and $+0.93 \mathrm{GJ} \mathrm{g}^{-1}$, respectively $\left(E_{\text {mix }}=1.6\right)$. The following discussion examines other reported values of $E_{\text {mix }}$. If they report different enhancements, then an adjustment would be warranted $\left(A_{\text {mix }} \neq 1\right)$. However, other models suggest similar values of $E_{\text {mix }}$. Jacobson (2000) found
$E_{\text {mix }}=2$ for core-shell particles compared with unmixed, spherical particles $\left(0.76\right.$ versus $\left.0.38 \mathrm{GJ} \mathrm{g}^{-1}\right)$. The greater $E_{\text {mix }}$ in this model is qualitatively predictable. His baseline case used spherical particles that have less absorption, while uncoated particles in CAM were given higher absorption because fresh black carbon particles are aggregates (Bond and Bergstrom, 2006). If we had used spherical particles in our unmixed case, $E_{\text {mix }}$ would have been about 1.8 (Bond et al., 2006). Figure 7 demonstrates the effect of $E_{\text {mix }}$, showing the increase between baseline SFP in our model and that of Jacobson (2001).

Chung and Seinfeld (2002) also modeled mixed particles that were internally homogeneous instead of having a more realistic core-shell configuration. $E_{\text {mix }}$ in their model was 1.6. A core-shell model with measured sizes (Moffett and Prather, 2009) found $E_{\text {mix }}$ of 1.4 to 1.6. Recent model results based on measured particle morphology rather than the coreshell assumption (Adachi et al., 2010) give values of about 1.4 for $E_{\text {mix }}$.

A recent model (Myhre et al., 2009) with an SFP of $+0.99 \mathrm{GJ} \mathrm{g}^{-1}$ was not included in the ensemble because it included a lengthened aging time based on observed oxidation rates (Maria et al., 2004). This change increases lifetime and hence SFP, but tying aging to oxidation rates ignores the rapid aging by coating (Moffett and Prather, 2009). Nevertheless, this research explored an aerosol mixing treatment similar to ours, resulting in $E_{\text {mix }}$ of 1.27. The lower increase in this model is also qualitatively reasonable. The slower aging rate means that a greater fraction of aerosol is unaged and unmixed, so a mixing treatment increases the forcing less. 
We conclude that the increase due to aerosol mixing in our model is reasonable. Although we can explain model differences qualitatively, because of the variation, we give $A_{\text {mix }}$ a value of $1.0 \pm 0.2$.

\subsection{Regional diversity: $E_{\text {region }}$ and $A_{\text {region }}$}

Predicted SFP differs among models due to some combination of forcing-per-mass and lifetime. It is reasonable to expect that diversity among regions might not be the same as those produced by CAM, so that the regional diversity in Fig. 4 could vary among models. Here, we develop ensemble adjustments that reflect regional variations. We define values of $E_{\text {region }}$ as the ratio between regional $\mathrm{SFP}^{\mathrm{BC}}$ and the most commonly reported value in regional studies: globalaverage $\mathrm{SFP}^{\mathrm{BC}}$ for energy-related emissions. The value chosen for the denominator of this ratio is illustrative, but it does not affect the final adjustment $\left(A_{\text {region }}\right)$, which is a ratio between the $E_{\text {region }}$ of various models and $E_{\text {region }}$ of the reference model. The $A_{\text {region }}$ will be applied to SFP of individual regions, and the globally-averaged SFP will be determined by emission-weighting the regional SFP values.

Figure 8 shows regional enhancements $\left(E_{\text {region }}\right)$, for $\mathrm{SFP}^{\mathrm{BC}}$ for $\mathrm{CAM}$ and four other models (Oslo-CTM, Berntsen et al., 2006 and Rypdal et al., 2009; GISS, Koch et al., 2007; MOZART, Naik et al., 2007; LMD, Reddy and Boucher, 2009). Energy-related forcing values for the model of Naik et al. (2007) were not available for their most recent model version, so we used a ratio to East Asian SFP derived from Saikawa et al. (2009; $\left.\mathrm{SFP}^{\mathrm{BC}}=+0.95 \mathrm{GJ} \mathrm{g}^{-1}\right)$. Regional definitions are not identical in each model, so the comparisons are not exact. Reddy and Boucher (2007); Berntsen et al. (2006) and Rypdal et al. (2009) modeled only energyrelated emissions, while Naik et al. (2007) examined only open burning.

For energy-related emissions in three regions (East Asia, North America, and Europe), the variation is low. The maximum and minimum values of $E_{\text {region }}$ for these regions are within $15 \%$. South Asia is different; the GISS model predicts very high regional enhancement, with the other models lying between GISS and CAM. In GISS and LMD, aerosol lifetime in South Asia is much higher than the global average, while CAM's lifetime is similar to the global average. Normalized forcing in the GISS model is similar to that in other regions. Thus, the high estimates from the GISS model are entirely due to aerosol lifetime, and the processes governing that lifetime should be constrained with observations. The available models, although limited in number, suggest that SFP is relatively well-constrained in temperate regions - within about $20 \%$. In tropical regions with deep convection, models differ in regional diversity, possibly due to parameterizations of convective removal and transport at high altitudes.

Regional enhancements are greater and more diverse for open burning emissions than for energy-related emissions. Temperate regions again agree better than tropical regions.
CAM and MOZART agree that $\mathrm{SFP}^{\mathrm{BC}}$ is elevated above energy-related emissions at northern latitudes. In addition to convective removal, emission injection height could differ among models; GISS and CAM emissions are injected into the boundary layer. $E_{\text {region }}$ from MOZART is much higher than that from CAM in South Asia and South America.

Most of our regional SFP enhancements for energy-related combustion are within $10 \%$ of other models. An exception is South Asia $\left(A_{\text {region }}=1.5\right)$. For biomass burning, we apply regional adjustments to South Asia, South America, and Africa $\left(A_{\text {region }}=1.4,1.25\right.$, and 0.8 , respectively). We choose uncertainties in $A_{\text {region }}$ based on model diversity, with high uncertainties also applied when regions have not been isolated in models: $15 \%$ for North America, Europe, and East Asia; $20 \%$ for Central and South America; $40 \%$ for South Asia, Middle East, and Africa. For open biomass burning in Europe, Northern Asia, and North America, we use a 15\% uncertainty, while South Asia, South America, and Africa have a $40 \%$ uncertainty.

Fewer studies are available for regional variations in forcing by OM (Berntsen et al., 2006; Naik et al., 2007; Koch et al., 2007). The studies broadly agree that SFP from South Asia, Africa and from biomass burning regions is of larger magnitude. Some unexplained factors include the slight positive SFP in Europe reported by Koch et al. (2007) and the factor of five to eight difference for biomass burning in Naik et al. (2007) as compared with that from East Asia by Saikawa et al. (2009) using the same model. Until these factors are sorted out, a true ensemble adjustment $\left(A_{\text {region }}\right)$ for $\mathrm{OM}$ is not possible. However, adjusting $\mathrm{SFP}^{\mathrm{BC}}$ and not $\mathrm{SFP}^{O M}$ for regional differences, many of which are attributable to aerosol lifetime, could overstate positive forcing by an aerosol mixture. With some misgivings, we apply the same regional adjustments given above for $\mathrm{BC}$ to the values for OM.

\subsection{Arctic transport and deposition}

Poleward transport and removal of $\mathrm{BC}$ has large uncertainties (Textor et al., 2006), affecting divisions between Arctic and extra-Arctic aerosol in Fig. 4. If our transport to the Arctic were too low, then forcing there will also be too low. Uncertainties in snow albedo change also affect the cryosphere forcing in Fig. 4.

Figure 9 shows the diversity of predicted deposition in the Arctic from Shindell et al. (2008) compared with our model results (red dots). Deposition in our model is near the ensemble median for North America and Europe, and comparatively low for aerosol from both East and South Asia. We use ensemble adjustment factors for spring, when impact is greatest (Flanner et al., 2007): $1.06 \pm 0.7$ for North America and Europe, $1.3 \pm 0.6$ for South Asia, and $2.4 \pm 1.0$ for East Asia. We apply these factors to the Arctic portion of cryosphere SFP only. In regions where CAM differs greatly from the median, the Arctic contribution is a small fraction of 


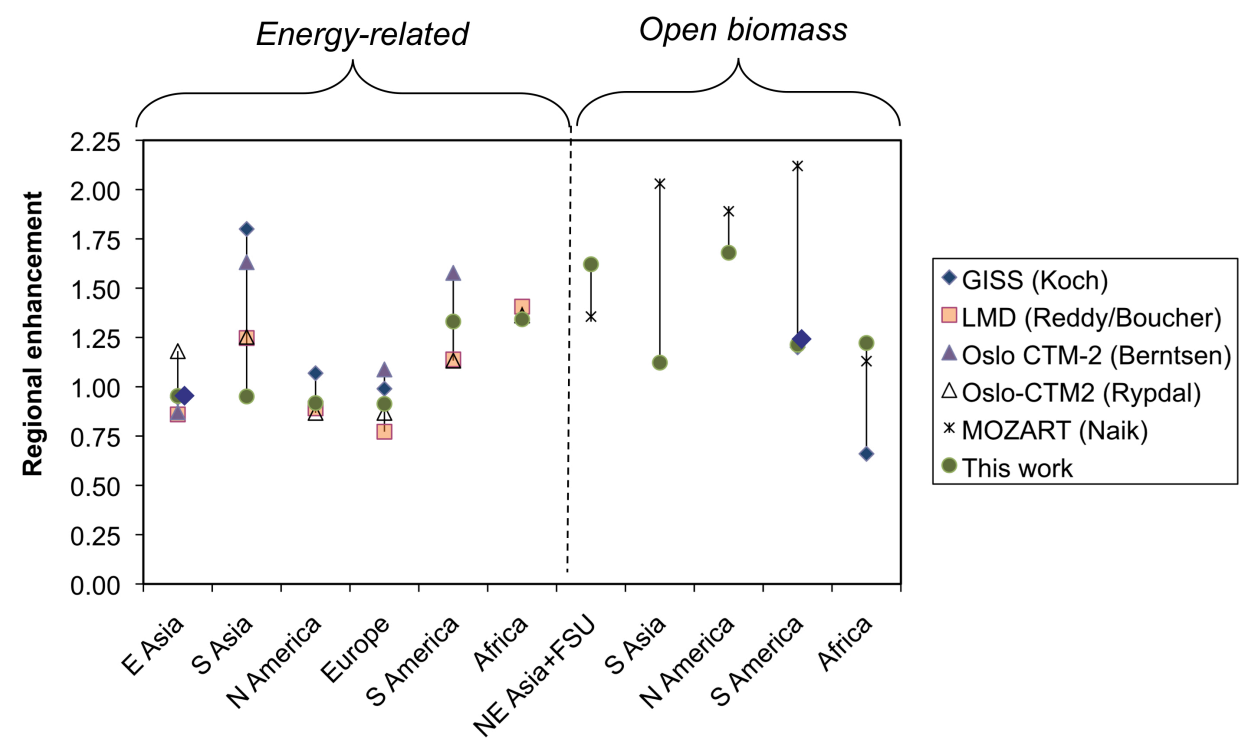

Fig. 8. Regional enhancement values for $\mathrm{SFP}_{\mathrm{dir}}$ from four models. Regional enhancement is the ratio between regional SFP and global average energy-related SFP. Oslo CTM-2 did not provide global average values, so East Asia is used as a normalizing region, because SFP for that region is close to the global average in other models.

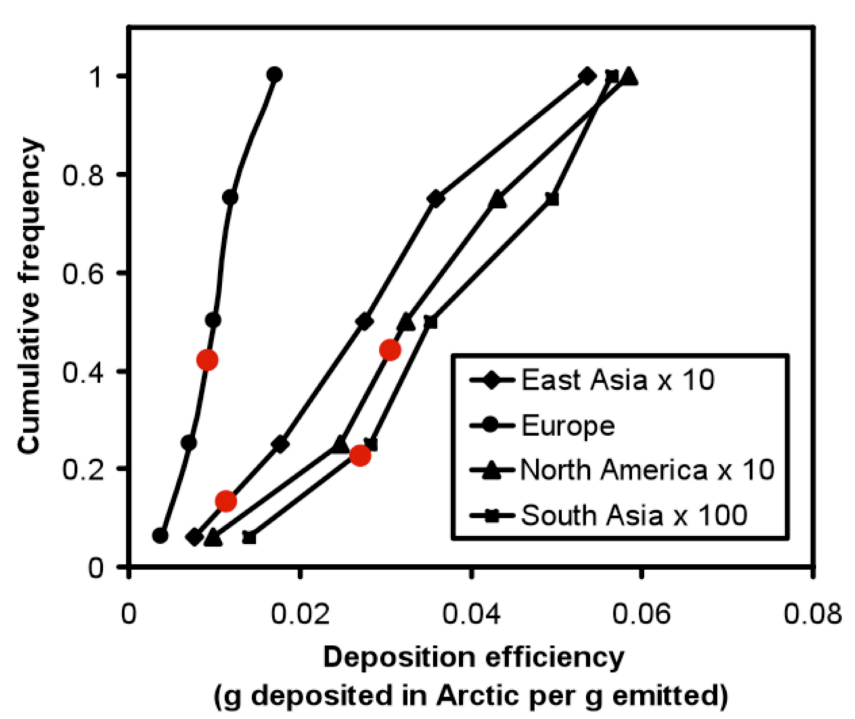

Fig. 9. Distribution of ensemble results for springtime Arctic deposition (March-April-May) (from Shindell et al., 2009), and comparison of CAM results (red dots).

SFP. The ensemble adjustment for East Asia increases total SFP by only $2 \%$ and the change for South Asia is negligible. This transport may be a large uncertainty in Arctic radiative impact, but it is not a large uncertainty in global impact.

\subsection{Total cryosphere forcing}

Estimates of ice and snow forcing are more variable than those of atmospheric forcing. Koch et al. (2009) summa- rized cryosphere forcing estimates, which range from +0.01 to $+0.16 \mathrm{~W} \mathrm{~m}^{-2}$ and vary widely with the method of parameterization and the reference value of emission. However, some of these estimates use different emission rates and some are less physically based. Only one of the estimates is higher than $+0.1 \mathrm{~W} \mathrm{~m}^{-2}$, and that value has been superceded. The lowest estimate comes from a model (GISS) that compared 1995 forcing with 1890. In addition, feedbacks make the response to cryosphere forcing highly uncertain. Cryosphere forcing in CAM is $+0.037 \mathrm{~W} \mathrm{~m}^{-2}$ from fossil fuel and biofuel, and $+0.047 \mathrm{~W} \mathrm{~m}^{-2}$ when open biomass burning is added (Flanner et al., 2009). Total fossil and biofuel emissions produce $+0.06 \mathrm{~W} \mathrm{~m}^{-2}$ in GATOR-GCM ( $A_{\text {base }, \text { cry }}=1.6$; Jacobson, 2004; Jacobson, M. Z., personal communication, 2006) and $+0.03 \mathrm{~W} \mathrm{~m}^{-2}$ in the GISS model $\left(A_{\text {base,cry }}=0.8\right)$. We conclude that the CAM values used for cryospheric SFP are in the mid-range, but the uncertainties are about $100 \%$. Sensitivity analyses by Flanner et al. (2007) give uncertainty as $60 \%$ due to three model assumptions, excluding emissions. We therefore choose a value of $A_{\text {cry, base }}=1.0 \pm 0.6$, which encompasses the two other physically-based model estimates.

\subsection{Best estimates of SFP for BC and OM}

In Table 1, we combine the factors discussed above to provide estimates of $\mathrm{SFP}_{\mathrm{atm}}$,dir by region. For $\mathrm{BC}$, the baseline ensemble adjustment $\left(A_{\text {ens, base }}\right)$ of $1.06 \pm 0.34$ and $A_{\text {ens,mix }}$ of $1.0 \pm 0.2$ are applied to each regional $\mathrm{SFP}^{\mathrm{BC}}$, as well the regional adjustments and uncertainties discussed in Sect. 4.4. Uncertainties are assumed to be independent and are added in quadrature. The substantial uncertainties in the baseline and 
Table 1. Ensemble-adjusted Specific Forcing Pulse (SFP) for black carbon and organic matter. Uncertainties for OM are asymmetric and are presented as ranges.

\begin{tabular}{|c|c|c|c|c|}
\hline & \multicolumn{3}{|c|}{ Black carbon SFP $\left(\mathrm{GJ} \mathrm{g}^{-1}\right)$} & \multirow[t]{2}{*}{ Organic matter SFP $\left(\mathrm{GJ} \mathrm{g}^{-1}\right)$} \\
\hline & Atmosphere & Cryosphere & Total & \\
\hline Average energy & $0.96 \pm 0.46$ & $0.15 \pm 0.11$ & $1.11 \pm 0.47$ & $-0.042(-0.02,-0.08)$ \\
\hline Canada & $0.82 \pm 0.34$ & $0.37 \pm 0.24$ & $1.19 \pm 0.42$ & $-0.021(-0.01,-0.04)$ \\
\hline USA & $0.83 \pm 0.35$ & $0.18 \pm 0.12$ & $1.01 \pm 0.37$ & $-0.031(-0.01,-0.06)$ \\
\hline Central America & $1.16 \pm 0.51$ & $0.03 \pm 0.02$ & $1.19 \pm 0.51$ & $-0.053(-0.02,-0.1)$ \\
\hline South America & $1.2 \pm 0.53$ & $0.02 \pm 0.01$ & $1.22 \pm 0.53$ & $-0.049(-0.02,-0.09)$ \\
\hline Northern Africa & $1.24 \pm 0.7$ & $0.08 \pm 0.05$ & $1.33 \pm 0.7$ & $-0.058(-0.02,-0.12)$ \\
\hline Western Africa & $1.22 \pm 0.69$ & $0.02 \pm 0.01$ & $1.24 \pm 0.69$ & $-0.062(-0.02,-0.12)$ \\
\hline Eastern Africa & $1.15 \pm 0.65$ & $0.02 \pm 0.01$ & $1.17 \pm 0.65$ & $-0.068(-0.02,-0.13)$ \\
\hline Southern Africa & $1.24 \pm 0.7$ & $0.01 \pm 0.01$ & $1.26 \pm 0.7$ & $-0.078(-0.03,-0.16)$ \\
\hline OECD Europe & $0.81 \pm 0.34$ & $0.16 \pm 0.13$ & $0.97 \pm 0.37$ & $-0.032(-0.02,-0.06)$ \\
\hline Eastern Europe & $0.87 \pm 0.37$ & $0.19 \pm 0.14$ & $1.05 \pm 0.39$ & $-0.037(-0.02,-0.07)$ \\
\hline Former USSR & $0.86 \pm 0.36$ & $0.5 \pm 0.34$ & $1.35 \pm 0.5$ & $-0.03(-0.01,-0.06)$ \\
\hline Middle East & $1.17 \pm 0.66$ & $0.18 \pm 0.11$ & $1.36 \pm 0.67$ & $-0.058(-0.02,-0.11)$ \\
\hline South Asia & $1.29 \pm 0.72$ & $0.13 \pm 0.08$ & $1.42 \pm 0.73$ & $-0.081(-0.03,-0.16)$ \\
\hline East Asia & $0.84 \pm 0.36$ & $0.18 \pm 0.15$ & $1.02 \pm 0.39$ & $-0.026(-0.01,-0.05)$ \\
\hline Southeast Asia & $0.96 \pm 0.54$ & $0.01 \pm 0.01$ & $0.98 \pm 0.54$ & $-0.045(-0.02,-0.09)$ \\
\hline Oceania & $0.99 \pm 0.56$ & $0.05 \pm 0.03$ & $1.03 \pm 0.56$ & $-0.056(-0.02,-0.11)$ \\
\hline Japan & $0.72 \pm 0.4$ & $0.07 \pm 0.04$ & $0.79 \pm 0.41$ & $-0.014(-0.01,-0.03)$ \\
\hline Average open & $1.16 \pm 0.63$ & $0.08 \pm 0.06$ & $1.23 \pm 0.63$ & $-0.074(-0.03,-0.15)$ \\
\hline Europe & $1.23 \pm 0.52$ & $0.2 \pm 0.15$ & $1.43 \pm 0.54$ & $-0.072(-0.03,-0.14)$ \\
\hline Northern Asia & $1.47 \pm 0.62$ & $0.59 \pm 0.45$ & $2.06 \pm 0.76$ & $-0.057(-0.03,-0.11)$ \\
\hline Southern Asia & $1.42 \pm 0.8$ & $0.03 \pm 0.02$ & $1.45 \pm 0.8$ & $-0.096(-0.03,-0.19)$ \\
\hline North America & $1.52 \pm 0.64$ & $0.37 \pm 0.32$ & $1.89 \pm 0.72$ & $-0.057(-0.03,-0.11)$ \\
\hline S/C America & $1.37 \pm 0.77$ & $0.01 \pm 0.01$ & $1.38 \pm 0.77$ & $-0.092(-0.03,-0.18)$ \\
\hline Africa & $0.88 \pm 0.5$ & $0.01 \pm 0.01$ & $0.9 \pm 0.5$ & $-0.061(-0.02,-0.12)$ \\
\hline Global average & $1.03 \pm 0.52$ & $0.12 \pm 0.09$ & $1.15 \pm 0.53$ & $-0.064(-0.02,-0.13)$ \\
\hline
\end{tabular}

mixing adjustments yield large uncertainties in regional SFP even when $A_{\text {rgn }}$ is low. We weight regional SFP by emission rate to provide a global average $\mathrm{SFP}_{\mathrm{dir}}^{\mathrm{BC}}$ of $1.03 \pm 0.52 \mathrm{GJ} / \mathrm{g}$.

For $\mathrm{SFP}_{\text {cry }}^{\mathrm{BC}}$, we apply the baseline uncertainties discussed in Sect. 4.6 and uncertainties in Arctic deposition discussed in Sect. 4.5. Average cryosphere SFP is $0.12 \pm 0.09$, although this varies greatly by region.

SFP for organic matter includes the baseline ensemble adjustment $(1.30$ with an uncertainty range of $[0.8,2.2])$ and the regional adjustments discussed in Sect. 4.4. As stated earlier, the asymmetric uncertainties are larger in the negative direction.

As $\mathrm{SFP}^{\mathrm{OM}}$ is negative, co-emissions of $\mathrm{OM}$ could offset positive forcing by BC. However, the magnitude of $\mathrm{SFP}_{\mathrm{dir}}^{\mathrm{BC}}$ is greater than that of $\mathrm{SFP}_{\mathrm{dir}}^{\mathrm{OM}}$ by about an order of magnitude. Figure 10 shows $\mathrm{SFP}_{\text {dir }}^{\mathrm{BC}}$ plotted against $\mathrm{SFP}_{\text {dir }}^{\mathrm{OM}}$ for each region. The nearly linear relationship between the two is unsurprising, because our model had similar treatments of removal for both species. However, the good relationship does suggest that lifetime $(\tau)$, more than varying forcing-per-mass $(f)$, is a dominant factor in determining SFP.
Relative emission rates of $\mathrm{OM}$ and $\mathrm{BC}$ differ by source, but the highest $\mathrm{OM}: \mathrm{BC}$ ratio from a dominant source type is 12:1 for open burning of biomass (see emission rates given in Sect. 5). The ratio of $\mathrm{SFP}_{\text {dir }}^{\mathrm{BC}}$ to $\mathrm{SFP}_{\mathrm{dir}}^{\mathrm{OC}}$ is greater than 12:1 for all regions, so the net effect of $\mathrm{BC}$ plus $\mathrm{OM}$ from that source is positive forcing. If only $\mathrm{OM}$ and $\mathrm{BC}$ were emitted, and direct plus cryosphere forcing were the only physical effect, an OM:BC ratio of about 15:1 would result in zero or positive top-of-atmosphere direct forcing for any region. Any lower ratio has direct radiative warming, and the "neutral" ratio is greater for emissions in some regions. Values of $\mathrm{SFP}_{\mathrm{dir}+\text { cry }}^{\mathrm{BC}}$ are also shown in Fig. 10. Given the large uncertainties discussed earlier, there is still a significant probability that some OM:BC ratios could result in cooling. This probability is lower when cryosphere forcing is significant.

The discussion here could suggest that all major BC sources are net warming, regardless of co-emissions of organic matter. However, other co-emitted species, and other physical effects must be included in the analysis before such conclusions are made. 


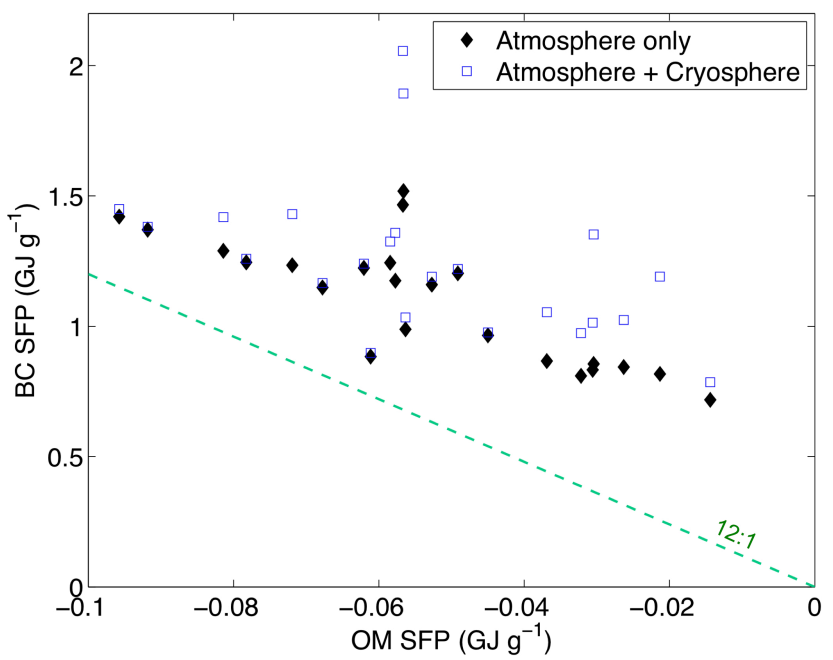

Fig. 10. SFP for black carbon plotted versus SFP for organic matter for all 23 source-region combinations. A line which intercepts the origin and which has a slope of the OM:BC ratio from a particular source divides direct warming from direct cooling (above/below) by that source. The 12:1 line is given here because that $\mathrm{OM}: \mathrm{BC}$ ratio is the highest of all the major sources. Therefore, central estimates for SFP indicate that the OM plus BC mix results in direct warming for all sources, although uncertainties are large.

\subsection{Caveats}

In our estimates of $\mathrm{SFP}_{\mathrm{TOA}, \mathrm{dir}+\mathrm{cry}}$, we adjust a reference model (CAM) using an ensemble that incorporates multiple models. This procedure accounts for the possibility that CAM could be biased relative to other models. However, it does not address the fact that all models could be biased relative to reality because of common, but incorrect, assumptions about aerosol behavior. A quantitative assessment of the second possibility is greatly needed. To proceed further, the underlying causes of variation within models should be identified and evaluated with measurements, and models that more closely reproduce critical observations should be given a higher weighting.

Additional treatments are also needed to account for emerging knowledge about the properties and impacts of black carbon and organic matter. We incorporated adjustments for black carbon mixing and regional dependence of forcing because of the availability of multiple model results. For black carbon mixing, there is also general agreement on the physical nature of the enhancement. However, we did not apply the same treatment to many other possible effects. One example of an effect that needs to be addressed for black carbon is enhanced forcing due to inclusions in cloud droplets (Jacobson, 2006). Examples for organic matter are absorption due to some types of organic compounds (Kirchstetter et al., 2004) and the emerging understanding of organic aerosol hygroscopicity and particle growth (Jimenez et al., 2009).

\section{Comparison of SFP with forcing and GWP values}

While the main purpose of this paper is to present SFP for BC and $\mathrm{OM}$, this measure has not previously appeared in the literature. To compare the values provided here to earlier work, we translate SFP to forcing and Global Warming Potential, as discussed in Sect. 2. Globally-averaged measures are shown in Table 2 by emission-weighting regional SFP. Forcing and GWP for emissions from each region can be developed from Table 1 using the procedures outlined here.

\subsection{Globally-averaged forcing}

We calculate total aerosol forcing as emission rate times SFP. Estimates of year 2000 energy-related emissions by Bond et al. (2007), plus updated emission factors, are $4.8 \mathrm{Tg} \mathrm{BC}$ and $15 \mathrm{Tg}$ OM. These values of OM include a source-dependent OM-to-OC ratio. The work presented earlier gives central values and uncertainties that are carried through SFP, the forcing per emission. Uncertainties in emission rates have been discussed extensively elsewhere (Bond et al., 2004), and we will not include them here. Multiplying the emission rates given above by the average SFP for energy-related emissions, converting units, and dividing by the area of the Earth gives $+0.33 \pm 0.22 \mathrm{~W} \mathrm{~m}^{-2}$ for BC (including cryosphere forcing) and $-0.04 \mathrm{~W} \mathrm{~m}^{-2}$ for $\mathrm{OM}$, with an asymmetric uncertainty range of $(-0.02,-0.08)$. Likewise, we obtain forcing by multiplying SFP for open-burning emissions with average emission rates from van der Werf et al. (2006) (2.6 Tg BC and $30 \mathrm{Tg} \mathrm{OM}$ ). For this source, we assume that organic matter is 1.4 times organic carbon for consistency with AeroCom emissions (Dentener et al., 2006). Forcing by open-burning emissions is is $+0.20 \pm 0.08 \mathrm{~W} \mathrm{~m}^{-2}$ for $\mathrm{BC}$, including cryosphere forcing, and $-0.14(-0.04$, $-0.27) \mathrm{W} \mathrm{m}^{-2}$ for OM, respectively. Table 2 summarizes these estimates and provides a breakdown between atmosphere and cryosphere.

IPCC (Forster et al., 2007) reports anthropogenic forcing, or the difference between present-day and an atmosphere with 1750 emissions. The net anthropogenic emissions given by Dentener et al. (2006) are: $4.2 \mathrm{Tg} \mathrm{BC}$ and 10.7 Tg OC from energy-related combustion, and $2.1 \mathrm{Tg} \mathrm{BC}$ and $21.9 \mathrm{Tg} \mathrm{OC}$ from open burning. These emission rates yield anthropogenic forcing of $+0.40 \pm 0.18 \mathrm{~W} \mathrm{~m}^{-2}$ for $\mathrm{BC}$ without cryosphere, $+0.44 \pm 0.29 \mathrm{~W} \mathrm{~m}^{-2}$ for $\mathrm{BC}$ with cryosphere, and $-0.13(-0.05,-0.25) \mathrm{W} \mathrm{m}^{-2}$ for OM.

Our anthropogenic aerosol forcing estimate of $+0.40 \mathrm{~W} \mathrm{~m}^{-2}$ for direct TOA forcing of total $\mathrm{BC}$ is $18 \%$ higher than the $+0.34 \mathrm{~W} \mathrm{~m}^{-2}$ given by IPCC (Forster et al., 2007). We consider this an improved estimate because it includes the increased absorption caused by in-particle mixing (see Sect. 4.1) and excludes duplicate model results. However, the increase is small because some models with mixing and with higher emission rates were already averaged in IPCC's estimate. The cryosphere contribution 
Table 2. Global average forcing and global warming potentials derived from SFP combined with estimates of emissions (aerosol and anthropogenic forcing) or carbon dioxide forcing (global warming potentials). Uncertainties for OM are asymmetric and are presented as ranges.

\begin{tabular}{lrrr}
\hline & $\begin{array}{r}\text { BC TOA } \\
\text { direct }\end{array}$ & $\begin{array}{r}\text { BC direct } \\
\text { +cryosphere }\end{array}$ & OM TOA direct \\
\hline Total aerosol forcing $\left(\mathrm{Wm}^{2}\right)$ & & & \\
\hline Global total & $0.47 \pm 0.26$ & $0.53 \pm 0.30$ & $-0.17(-0.07,-0.35)$ \\
Open biomass & $0.19 \pm 0.07$ & $0.20 \pm 0.08$ & $-0.14(-0.05,-0.27)$ \\
Energy-related & $0.28 \pm 0.19$ & $0.33 \pm 0.22$ & $-0.04(-0.02,-0.08)$ \\
\hline Anthropogenic forcing with & & & \\
IPCC-AR4 emissions $\left(\mathrm{Wm}^{2}\right)$ & & & \\
\hline Global total & $0.40 \pm 0.18$ & $0.44 \pm 0.29$ & $-0.13(-0.05,-0.25)$ \\
Open biomass & $0.15 \pm 0.06$ & $0.16 \pm 0.13$ & $-0.10(-0.04,-0.20)$ \\
Energy-related & $0.25 \pm 0.12$ & $0.29 \pm 0.16$ & $-0.03(-0.01,-0.06)$ \\
\hline Global warming potential, 100-year & & & \\
\hline Global average & $740 \pm 370$ & $830 \pm 440$ & $-46(-18,-92)$ \\
Open biomass & $830 \pm 330$ & $880 \pm 370$ & $-53(-20,-100)$ \\
Energy-related & $690 \pm 450$ & $790 \pm 530$ & $-30(-12,-60)$ \\
\hline Global warming potential, 20-year & & & \\
\hline Global average & $2600 \pm 1300$ & $2900 \pm 1500$ & $-160(-60,-320)$ \\
Open biomass & $2900 \pm 1100$ & $3100 \pm 1300$ & $-180(-70,-360)$ \\
Energy-related & $2400 \pm 1600$ & $2800 \pm 1800$ & $-110(-40,-210)$ \\
\hline
\end{tabular}

$\left(+0.05 \mathrm{~W} \mathrm{~m}^{-2}\right)$ is smaller than IPCC's estimate because it includes new, more physically based studies.

\subsection{Comparison with Global Warming Potential}

Previously, measures of forcing-per-emission have been presented as GWP values. For comparison, Table 2 shows GWPs calculated for 100-year and 20-year time horizons by dividing SFP by $1.4 \times 10^{-3} \mathrm{GJ} \mathrm{g}^{-1}$ and $4.0 \times 10^{-4} \mathrm{GJ} \mathrm{g}^{-1}$, respectively (see Sect. 2.5). In this discussion, we refer mainly to 100-year GWP values. The ratio of 100-year GWPs between two studies would be identical to the ratio of 20-year GWP values.

Compared with previous estimates of $\mathrm{GWP}^{\mathrm{BC}}$ by our group (Bond and Sun, 2005), the globally averaged value for direct forcing is similar but slightly higher $(740 \pm 370$ vs. 680). Uncertainties are about $50 \%$ of the total for BC. Direct $\mathrm{GWP}^{\mathrm{BC}}$ for energy-related emissions (fossil fuel and biofuel) is somewhat lower than for open burning (690 vs. 830). Our atmospheric 100 -year GWP ${ }^{\mathrm{BC}}$ from energy-related emissions is about $40 \%$ higher than the global mean average calculated by Reddy and Boucher (2007) and Fuglestvedt et al. (2009), who provided values of 480 and 460, respectively. The difference occurs largely because their models did not include internal mixing of black carbon with other aerosol components. As with direct forcing, addition of the cryosphere component increases globally-averaged GWP by about $10 \%$. This increase is regionally dependent, as can be inferred from Fig. 10.

Our value of $\mathrm{GWP}^{\mathrm{OM}}$ is -46 with an uncertainty range of $(-18,-92)$. The average value for open burning $(-53)$ is $80 \%$ greater than for energy-related combustion $(-30)$ because of seasonality. Fuglestvedt et al. (2009) used the same multi-model ensemble as we did, so their 100-year GWP for organic matter should be directly comparable. They provide a value of -69 for organic carbon; assuming that organic matter (which includes oxygen and hydrogen) is 1.4 times organic carbon by mass, their value becomes -49 , very similar to ours.

Reddy and Boucher (2007) reported a very large warming contribution from snow albedo for European emissions about a factor of two increase above atmospheric warming. This estimate is much higher than ours because they assumed a global average snow forcing of $+0.1 \mathrm{~W} \mathrm{~m}^{-2}$, a relatively high estimate. They also apportioned all snow forcing according to Arctic deposition of energy-related emissions, although much of the albedo impact is caused by open biomass burning $(25 \%)$ and $80 \%$ of the remainder occurs outside of the Arctic. We find that adding snow forcing increases warming by atmospheric BC by only $20-25 \%$ for Europe. Other emissions, particularly energy-related emissions in the former USSR and open biomass burning in Siberia (N Asia), give much larger warming by snow deposition. 


\section{Outlook, challenges, and caveats}

In this paper, we compare modeled estimates for atmospheric and snow forcing of black and organic carbon, normalizing to emission rates. Our measure is a simple combination of model outputs, the Specific Forcing Pulse. It quantifies the impact per emission from a particular region, either for a global total or within a region, and can be easily translated to other policy-relevant measures. We recommend a method of combining model diversity with model improvements to provide best estimates.

The discussion throughout this paper has demonstrated that forcing values depend critically on emission rate for SLCFs. One should examine varying forcing estimates in light of the emission inventory used to obtain them, as that choice alone may account for large differences. For example, estimates of black carbon forcing for energy-related emissions alone have been compared with estimates for all emissions, and anthropogenic forcing (which excludes emissions in 1750) has been compared with total forcing. These variations reflect disagreement about source strength as well as model physics, and the sources of variation. Likewise, observationally-based estimates of forcing (e.g. Sato et al., 2003; Yu et al., 2006; Ramanathan and Carmichael, 2008) inherently include all emissions, not just those assumed in the model used. When observed and modeled forcing estimates differ, discrepancies could result from lifetime, normalized forcing, emissions, or some combination. Reducing uncertainties will require isolating the underlying reasons for disagreement and addressing them through focused measurements.

Because of continuing interest in SLCFs and their mitigation, model estimates of total, sectoral or individual-source forcing are becoming common. To place new estimates in context of others' work, individual model results should always be accompanied by a comparison with model ensembles. Such comparisons should use normalized values, such as SFP, normalized forcing, or lifetime.

The SFP presented here incorporates model estimates of atmospheric and snow forcing. Future analysis should focus on two improvements:

Cloud changes. Changes in aerosol emissions also cause differences in cloud albedo ("first indirect"), cloud lifetime ("second indirect"), and cloud amount due to atmospheric heating ("semi-direct"). Such changes often result in negative forcing (Chen et al., 2010; Koch and DelGenio, 2010), which would reduce the magnitude of the SFP for black carbon, and make that of organic carbon even more negative. There is a dearth of model studies examining cloud responses to emission changes, rather than total impacts. Such studies are needed before any measure can incorporate these important effects.

Incorporating observations. The possibility that all models could be incorrect is a serious one. Observational constraints and uncertainties should be embedded in the SFP.
Not present in our discussion is a recent model estimate of very high atmospheric forcing by black carbon (Ramanathan and Carmichael, 2008). Their reported total forcing of $+0.9 \mathrm{~W} \mathrm{~m}^{-2}$ is higher than many other modeled estimates. However, because the estimate was partly based on observations, the large observed forcing could also result from actual emissions being higher than modeled emissions. Until the exact causes of difference are isolated, such estimates cannot be used to provide an "impact-per-emission" measure like the SFP. However, the great difference from modeled values should serve as a caution that emissions, model processes, or both contain uncertainties that are not fully reflected in global simulations.

\section{Appendix A}

\section{Quantifying immediate radiative forcing by black carbon and organic matter with the Specific Forcing Pulse}

Although global chemical-transport models usually do not use pulse emission functions, SFP can be determined from their output, with some limitations. In this section, we demonstrate why this is so using the simple box model shown in Figure A1. In this box, a first-order process with rate constant $1 / \tau^{S}$ is responsible for all removal. The solution to the first-order differential equation describing the concentration has a familiar exponential form. After an emission pulse of magnitude $M_{0}^{S}$ into the box, the integrated concentration from zero to infinity is $\tau^{S} M_{0}^{S}$. This integrated concentration is equivalent to the integral of burden $\left(b^{S}\right)$ over surface area and time in Equation 1. If the mass that remains in the box captures energy per time per mass $f^{S}$, the integrated energy for a box is $\left(\tau^{S} f^{S} M_{0}^{S}\right)$, and the added energy per emitted mass is $\left(\tau^{S} f^{S}\right)$. This would be the calculated SFP for the material in the box model. A positive sign indicates net energy capture, retention, or increase; a negative sign indicates energy rejection, which may occur either by reflection of energy or increased re-emission. In the same box at steady state with a continuous emission rate $\bar{M}^{S}\left(\mathrm{~g} \mathrm{~s}^{-1}\right)$, the steady-state concentration is $\left(\tau^{S} \bar{M}^{S}\right)$ and the rate of energy addition (or loss) is given by $\left(\tau^{S} f^{S} \bar{M}^{S}\right)$. The latter is commonly called forcing, and the forcing per mass is $\left(\tau^{S} f^{S}\right)$, which also happens to be SFP. Figure A1b illustrates some of the relationships between $\tau^{S} f^{S}$ (or SFP) and more commonly reported measures such as column burden $b^{S}$, emission rate $\bar{M}^{S}$, and total forcing.

After a change in emission, $95 \%$ of the change between the initial value and a steady-state value is achieved within (3 $\tau$ p. For SLCFs, atmospheric concentrations are always near equilibrium with respect to emission rates. The equilibrium requirement is more challenging for longer-lived species. For example, about 27 years of constant emissions are required to 


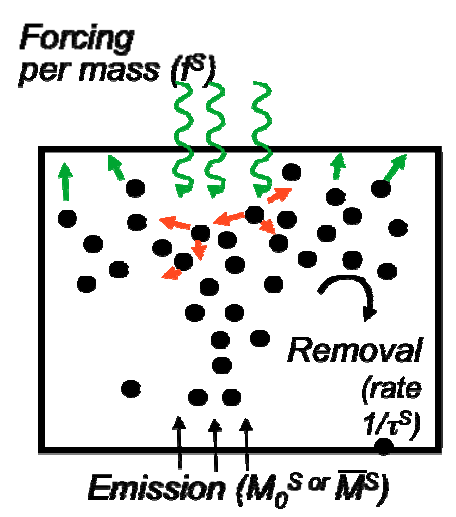

(a) Simple box model

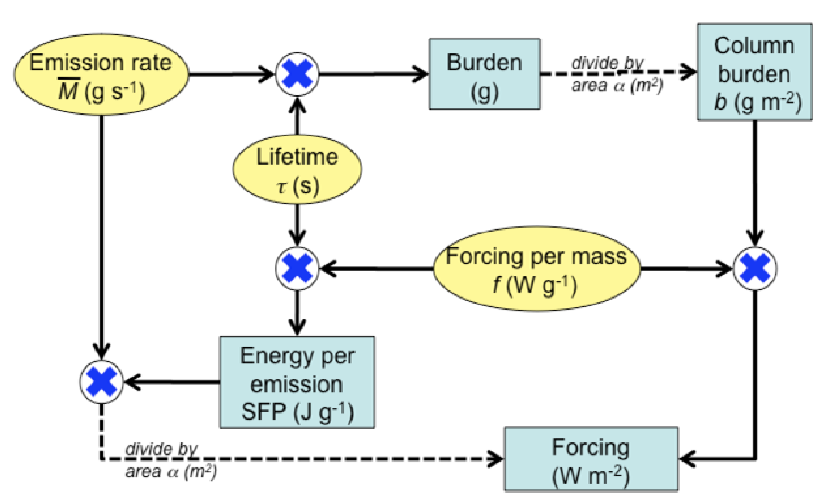

(b) Calculation

Fig. A1. (a) Simple box model demonstrating factors that govern impacts on energy balance due to addition of a species $S$. Net energy addition per mass $\left(f_{S}\right)$ is shown by green arrows indicating incoming and reflected solar radiation, and red arrows indicating absorption and dissipation as heat. Other interactions with radiation (e.g. re-emission of infrared energy, absorption by the species on the Earth's surface) can be framed in similar terms but are not presented here. First-order removal has rate constant 1/S (inverse of lifetime). (b) Calculation flow for box in steady state, with blue " $x$ " indicating multiplication (e.g., total burden = lifetime multiplied by emission rate). Energy added (Specific Forcing Pulse) does not depend on emission rate.

achieve steady-state conditions for a pollutant with a lifetime of 9 years. Thus, even if we chose to apply the SFP concept to methane, using global models to determine its value would require multi-decade simulations.

Of course, in the Earth system, $\tau^{S}, f^{S}$, and emission rate all vary in space and time. SFP derived from modeled forcing-to-emission ratios could depend on the emission spatial and temporal distributions used in the model, among other factors. Annually-averaged concentrations and forcing from chemical-transport models can provide average values of SFP, but the same model experiments cannot isolate seasonally-dependent values of SFP. Instantaneous values of $f^{S}$ can be derived from the ratio between total forcing and column burden at any time during the simulation. However, $\tau^{S}$ (the other component of SFP) cannot be obtained by dividing instantaneous values of burden and emission rate. Nevertheless, values of $\tau^{S}$ and $f^{S}$ can aid in diagnosing reasons for differences in SFP between seasons or regions.

\section{Appendix B}

\section{SFP and temperature change}

Locations of SLCF concentrations and forcing depend upon the emitting region (Berntsen et al., 2006). Furthermore, regional forcing is not proportional to regional temperature response. As a first step in representing this complex situation, we propose the following equation:

$I_{k}(t)=\int_{0}^{\tau} \sum_{j=1}^{J}\left(R_{k, j} \cdot \gamma_{j}^{S} \sum_{i=1}^{I}\left(\mathrm{SFP}_{j, i}^{S} \cdot e_{i}(t)\right)\right) d t$ where $\mathrm{SFP}_{j, i}^{S}$ is the forcing in region $j$ due to an emission of $S$ in region $i, \gamma_{j}^{S}$ is the ratio between effective forcing and radiative forcing and accounts for the "fast response" (Shine et al., 2003; Forster and Taylor, 2006; Lohmann et al., 2010) to species $S$ in region $j$, and $R_{k, j}^{S}$ is the response in region $k$ to a $\mathrm{CO}_{2}$-like forcing in region $j$ after time $t$. The term $\gamma^{S}$ encompasses some, but not all, of the effects that are traditionally called "efficacy" or "efficiency."

In matrix form,

$\boldsymbol{I}=\int_{0}^{\tau} \boldsymbol{R}(t) \cdot \gamma^{S} \cdot \mathbf{S F P}^{S} \cdot \boldsymbol{e}^{S}(t) d t$

where $\boldsymbol{I}$ is a vector in which the $k$-th element represents impact in region $k$, and $\boldsymbol{e}$ is a vector in which the $i$-th element represents emission in region $i$. SFP is a matrix for which the $j$-th row and $i$-th column represent forcing in region $j$ due to emission in region $i ; \gamma$ is a diagonal matrix; and $\mathbf{R}$ is a matrix for which the $k$-th row and $j$-th column give the response (temperature response or other chosen change) to forcing in region $j$. We note that the "regions" in the equation could be smaller than the large regions presented in this paper, even as small as a city. However, uncertainties in atmospheric transport and impact may preclude such detailed estimates of SFP.

Equations (B1) and (B2) explicitly represent the process in transient climate models. Models are diverse in their forcing estimates and climate responses, but many models provide only some elements of the equation. Some represent forcing only, while some add climate response. Furthermore, there is a wide range of predicted future emission trajectories. Identifying each component of the calculation from emission to climate response will allow many models to contribute to a 
final estimate of impact. Although Eqs. (B1) and (B2) may not capture nonlinearities, we suggest that it is better than ignoring regional differences.

Some measures have been proposed to examine the temperature response to mitigation decisions. Most notable is the Global Temperature Potential, which includes the temperature response to a pulse emission (Shine et al., 2005; Fuglestedvt et al., 2009) or to a sustained emission cut (Boucher and Reddy, 2008). Both measures require assuming the "mitigation" emission rate as a function of time, as well as a baseline rate for comparison. The difference between any two such trajectories is probably neither a pulse nor a constant. Instead, a measure that reflects the near-instantaneous forcing resulting from emissions (such as SFP) can be convolved with the time-dependent emission change $\left[e^{S}(\mathrm{t})\right]$ and the temperature response to radiative forcing to obtain a temperature response to a particular measure, as was done by Boucher and Reddy (2008).

Acknowledgements. This research was supported by the US EPA's Climate Office, the National Aeronautics and Space Administration under MAP (DMK) and NNG04GL91G (TCB), and by a UCAR ASP post-doctoral fellowship (MGF). Model runs were accomplished at the National Center for Atmospheric Research, sponsored by the National Science Foundation. We thank Steven J. Smith, John Bachmann, David Fahey, and Piers Forster for helpful comments, as well as anonymous and named reviewers for pointing out many needed clarifications. This paper has not been subjected to EPA's required peer and policy review and therefore does not necessarily reflect the views of the Agency. No official endorsement should be inferred.

Edited by: Y. Balkanski

\section{References}

Ackerman, T. P. and Toon, O. B.: Absorption of visible radiation in atmosphere containing mixtures of absorbing and nonabsorbing particles, Appl. Opt., 20, 3661-3667, 1981.

Adachi, K., Chung, S. H., and Buseck, P. R.: Shapes of soot aerosol particles and implications for their effects on climate, J. Geophys. Res.-Atmos., 115, D15206, doi:10.1029/2009jd012868, 2010.

Alcamo, J., van den Born, G. J., Bouwman, A. F., de Haan, B. J., Klein Goldewijk, K., Klepper, O., Krabec, J., Leemans, R., Olivier, J. G. J., Toet, A. M. C., Vries, H. J. M. d., and Woerd, H. J. v. d.: Modeling the global society-biosphere-climate system: Part 2: Computed scenarios, Water Air Soil Poll., 76, 37-78, 1994.

Berntsen, T., Fuglestvedt, J., Myhre, G., Stordal, F., and Berglen, T. F.: Abatement of greenhouse gases: does location matter?, J. Clim., 74, 377-411, 2006.

Bond, T. C. and Bergstrom, R. W.: Light absorption by carbonaceous particles: an investigative review, Aerosol Sci. Tech., 40, 27-67, 2006.
Bond, T. C. and Sun, H.: Can reducing black carbon emissions counteract global warming?, Environ. Sci. Tech., 39, 5921-5926, 2005.

Bond, T. C., Streets, D. G., Yarber, K. F., Nelson, S. M., Woo, J.-H., and Klimont, Z.: A technology-based global inventory of black and organic carbon emissions from combustion, J. Geophys. Res., 109, D14203, doi:14210.11029/12003JD003697, 2004.

Bond, T. C., Habib, G., and Bergstrom, R. W.: Limitations in the enhancement of visible light absorption due to mixing state, J. Geophys. Res., 111, D20211, doi:20210.21029/22006JD007315, 2006.

Bond, T. C., Bhardwaj, E., Dong, R., Jogani, R., Jung, S., Roden, C., Streets, D. G., Fernandes, S., and Trautmann, N.: Historical emissions of black and organic carbon aerosol from energyrelated combustion, 1850-2000, Glob. Biogeochem. Cyc., 21, GB2018, doi:2010.1029/2006GB002840, 2007.

Boucher, O. and Reddy, M. S.: Climate trade-off between black carbon and carbon dioxide emissions, Energ. Policy, 36, 193200, 2008.

Chen, W.-T., Lee, Y. H., Adams, P. J., Nenes, A., and Seinfeld, J. H.: Will black carbon mitigation dampen aerosol indirect forcing? Geophys. Res. Lett., 37(9), L09801, doi:10.1029/2010GL042886, 2010.

Chung, C. E., Ramanathan, V., and Kiehl, J. T.: Effects of the South Asian absorbing haze on the northeast monsoon and surface - air heat exchange, J. Clim., 15, 2462-2476, 2002.

Chung, S. H. and Seinfeld, J. H.: Global distribution and climate forcing of carbonaceous aerosols, J. Geophys. Res., 107, 44074441, 2002.

Collins, W. D., Rasch, P. J., Boville, B. A., Hack, J. J., McCaa, J. R., Williamson, D. L., and Briegleb, B. P.: The formulation and atmospheric simulation of the Community Atmosphere Model Version 3 (CAM3), J. Clim., 19, 2144-2161, 2006.

Dentener, F., Kinne, S., Bond, T., Boucher, O., Cofala, J., Generoso, S., Ginoux, P., Gong, S., Hoelzemann, J. J., Ito, A., Marelli, L., Penner, J. E., Putaud, J.-P., Textor, C., Schulz, M., van der Werf, G. R., and Wilson, J.: Emissions of primary aerosol and precursor gases in the years 2000 and 1750 prescribed data-sets for AeroCom, Atmos. Chem. Phys., 6, 4321-4344, doi:10.5194/acp6-4321-2006, 2006.

Fasullo, J. T. and Trenberth, K. E.: The annual cycle of the energy budget. Part I: Global mean and land-ocean exchanges, J. Clim., 21, 2297-2312, doi:10.1175/2007jcli1935.1, 2008.

Flanner, M. G., Zender, C. S., Randerson, J. T., and Rasch, P. J.: Present-day climate forcing and response from black carbon in snow, J. Geophys. Res., 112, D11202, doi:11210.11029/12006JD008003, 2007.

Flanner, M. G., Zender, C. S., Hess, P. G., Mahowald, N. M., Painter, T. H., Ramanathan, V., and Rasch, P. J.: Springtime warming and reduced snow cover from carbonaceous particles, Atmos. Chem. Phys., 9, 2481-2497, doi:10.5194/acp-9-24812009, 2009.

Forster, P. M. D. and Taylor, K. E.: Climate forcings and climate sensitivities diagnosed from coupled climate model integrations, J. Clim., 19, 6181-6194, 2006.

Forster, P., Ramaswamy, V., Artaxo, P., Berntsen, T., Betta, R., Fahey, D. W., Haywood, J., Lean, J., Lowe, D. C., Myhre, G., Nganga, J., Prinn, R., Raga, G., Schulz, M., and Van Dorland, $\mathrm{R}$.: Changes in atmospheric constituents and in radiative forcing, 
in: Climate change 2007: The physical science basis, edited by: Solomon, S., Qin, D., Manning, M., Chen, Z., Marquis, M., Averyt, K. B., Tigor, M., and Miller, H. L., Cambridge University Press, Cambridge, UK, 129-234, 2007.

Fuglestvedt, J. S., Shine, K. P., Berntsen, T., Cook, J., Lee, D. S., Stenke, A., Skeie, R. B., Velders, G. J. M., and Waitz, I. A.: Transport impacts on atmosphere and climate: Metrics, Atmos. Env., 44, 4648-4677, doi:10.1016/j.atmosenv.2009.04.044, 2010.

Grieshop, A. P., Reynolds, C. C. O., Kandlikar, M., and Dowlatabadi, H.: A black-carbon mitigation wedge, Nat. Geosci., 2, 533-534, 2009.

Hansen, J. and Nazarenko, L.: Soot climate forcing via snow and ice albedos, Proc. Natl. Acad. Sci., 101, 423-428, 2004.

Hansen, J., Sato, M., and Ruedy, R.: Radiative forcing and climate response, J. Geophys. Res.-Atmos., 102, 6831-6864, 1997.

Hansen, J. E., Sato, M., Ruedy, R., Lacis, A., and Oinas, V.: Global warming in the twenty-first century: an alternative scenario, Proc. Natl. Acad. Sci., 97, 9875-9880, 2000.

Hansen, J., Sato, M., Ruedy, R., Nazarenko, L., Lacis, A., Schmidt, G. A., Russell, G., Aleinov, I., Bauer, M., Bauer, S., Bell, N., Cairns, B., Canuto, V., Chandler, M., Cheng, Y., Del Genio, A., Faluvegi, G., Fleming, E., Friend, A., Hall, T., Jackman, C., Kelley, M., Kiang, N., Koch, D., Lean, J., Lerner, J., Lo, K., Menon, S., Miller, R., Minnis, P., Novakov, T., Oinas, V., Perlwitz, J., Rind, D., Romanou, A., Shindell, D., Stone, P., Sun, S., Tausnev, N., Thresher, D., Wielicki, B., Wong, T., Yao, M., and Zhang, S.: Efficacy of climate forcings, J. Geophys. Res.-Atmos., 110, D18104, doi:18110.11029/12005jd005776, 2005.

Jacobson, M. Z.: A physically-based treatment of elemental carbon optics: implications for global direct forcing of aerosols, Geophys. Res. Let., 27, 217-220, 2000.

Jacobson, M. Z.: Climate response of fossil fuel and biofuel soot, accounting for soot's feedback to snow and sea ice albedo and emissivity, J. Geophys. Res., 109, D21201, doi:21210.21029/22004JD004945, 2004.

Jacobson, M. Z.: Effects of absorption by soot inclusions within clouds and precipitation on global climate, J. Phys. Chem., 110, 6860-6873, 2006.

Jimenez, J. L., Canagaratna, M. R., Donahue, N. M., Prevot, A. S. H., Zhang, Q., Kroll, J. H., DeCarlo, P. F., Allan, J. D., Coe, H., Ng, N. L., Aiken, A. C., Docherty, K. S., Ulbrich, I. M., Grieshop, A. P., Robinson, A. L., Duplissy, J., Smith, J. D., Wilson, K. R., Lanz, V. A., Hueglin, C., Sun, Y. L., Tian, J., Laaksonen, A., Raatikainen, T., Rautiainen, J., Vaattovaara, P., Ehn, M., Kulmala, M., Tomlinson, J. M., Collins, D. R., Cubison, M. J., Dunlea, E. J., Huffman, J. A., Onasch, T. B., Alfarra, M. R., Williams, P. I., Bower, K., Kondo, Y., Schneider, J., Drewnick, F., Borrmann, S., Weimer, S., Demerjian, K., Salcedo, D., Cottrell, L., Griffin, R., Takami, A., Miyoshi, T., Hatakeyama, S., Shimono, A., Sun, J. Y., Zhang, Y. M., Dzepina, K., Kimmel, J. R., Sueper, D., Jayne, J. T., Herndon, S. C., Trimborn, A. M., Williams, L. R., Wood, E. C., Middlebrook, A. M., Kolb, C. E., Baltensperger, U., and Worsnop, D. R.: Evolution of Organic Aerosols in the Atmosphere, Science, 326, 1525-1529, doi:10.1126/science.1180353, 2009.

Jones, A., Haywood, J. M., and Boucher, O.: Aerosol forcing, climate response and climate sensitivity in the Hadley Centre climate model, J. Geophys. Res.-Atmos., 112, D20211, doi:10.1029/2007jd008688, 2007.

Kirchstetter, T. W., Novakov, T., and Hobbs, P. V.: Evidence that the spectral dependence of light absorption by aerosols is affected by organic carbon, J. Geophys. Res., 109, D21208, doi:21210.21029/22004JD004999, 2004.

Koch, D. and Del Genio, A.: Black carbon absorption effects on cloud cover, review and synthesis, Atmos. Chem. Phys. Discuss., 10, 7323-7346, doi:10.5194/acpd-10-7323-2010, 2010.

Koch, D., Bond, T. C., Streets, D., Unger, N., and van der Werf, G. R.: Global impacts of aerosols from particular source regions and sectors, J. Geophys. Res., 112, D02205, doi:02210.01029/02005JD007024, 2007.

Koch, D., Menon, S., Del Genio, A., Ruedy, R., Alienov, I., and Schmidt, G. A.: Distinguishing aerosol impacts on climate over the past century, J. Clim., 22, 2659-2677, doi:10.1175/2008jcli2573.1, 2009.

Kopp, R. E. and Mauzerall, D. L.: Assessing the climatic benefits of black carbon mitigation, Proc. Natl. Acad. Sci., 107, 1170311708, doi:10.1073/pnas.0909605107, 2010.

Lohmann, U., Rotstayn, L., Storelvmo, T., Jones, A., Menon, S., Quaas, J., Ekman, A. M. L., Koch, D., and Ruedy, R.: Total aerosol effect: radiative forcing or radiative flux perturbation?, Atmos. Chem. Phys., 10, 3235-3246, doi:10.5194/acp-10-32352010, 2010.

Maria, S. F., Russell, L. M., Gilles, M. K., and Myneni, S. C. B.: Organic aerosol growth mechanisms and their climate-forcing implications, Science, 306, 1921-1924, 2004.

Meehl, G. A., Arblaster, J. M., and Collins, W. D.: Effects of black carbon aerosols on the Indian Monsoon, J. Clim., 21, 2869-2882, 2008.

Moffet, R. C. and Prather, K. A.: In-situ measurements of the mixing state and optical properties of soot with implications for radiative forcing estimates, Proc. Natl. Acad. Sci., 106, 1187211877, 2009.

Murphy, D. M., Solomon, S., Portmann, R. W., Rosenlof, K. H., Forster, P. M., and Wong, T.: An observationally based energy balance for the Earth since 1950, J. Geophys. Res.-Atmos., 114, D17107, doi:10.1029/2009jd012105, 2009.

Myhre, G., Berglen, T. F., Johnsrud, M., Hoyle, C. R., Berntsen, T. K., Christopher, S. A., Fahey, D. W., Isaksen, I. S. A., Jones, T. A., Kahn, R. A., Loeb, N., Quinn, P., Remer, L., Schwarz, J. P., and Yttri, K. E.: Modelled radiative forcing of the direct aerosol effect with multi-observation evaluation, Atmos. Chem. Phys., 9, 1365-1392, doi:10.5194/acp-9-1365-2009, 2009.

Naik, V., Mauzerall, D. L., Horowitz, L. W., Schwarzkopf, M. D., Ramaswamy, V., and Oppenheimer, M.: On the sensitivity of radiative forcing from biomass burning aerosols and ozone to emission location, Geophys. Res. Let., 34, L03818, doi:10.1029/2006g1028149, 2007.

Quinn, P. K., Bates, T. S., Baum, E., Doubleday, N., Fiore, A. M., Flanner, M., Fridlind, A., Garrett, T. J., Koch, D., Menon, S., Shindell, D., Stohl, A., and Warren, S. G.: Short-lived pollutants in the Arctic: their climate impact and possible mitigation strategies, Atmos. Chem. Phys., 8, 1723-1725, 2008, http://www.atmos-chem-phys.net/8/1723/2008/.

Ramanathan, V. and Carmichael, G.: Global and regional climate changes due to black carbon, Nat. Geosci., 1, 221-227, 2008.

Reddy, M. S. and Boucher, O.: Climate impact of black carbon emitted from energy consumption in the world's regions, Geo- 
phys. Res. Let., 34, L11802, doi:11810.11029/12006GL028904, 2007.

Rypdal, K., Rive, N., Berntsen, T., Fagerli, H., Klimont, Z., Mideksa, T. K., and Fuglestvedt, J. S.: Climate and air qualitydriven scenarios of ozone and aerosol precursor abatement, Environ. Sci. Policy., 12, 855-869, doi:10.1016/j.envsci.2009.08.002, 2009.

Saikawa, E., Naik, V., Horowitz, L. W., Liu, J., and Mauzerall, D. L.: Present and potential future contributions of sulfate, black and organic carbon aerosols from China to global air quality, premature mortality and, radiative forcing, Atmos. Env., 43, 28142822, doi:10.1016/j.atmosenv.2009.02.017, 2009.

Sato, M., Hansen, J., Koch, D., Lacis, A., Ruedy, R., Dubovik, O., Holben, B., Chin, M., and Novakov, T.: Global atmospheric black carbon inferred from AERONET, Proc. Natl. Acad. Sci., 100, 6319-6324, 2003.

Schnaiter, M., Linke, C., Möhler, O., Naumann, K.-H., Saathoff, H., Wagner, R., Schurath, U., and Wehner, B.: Absorption amplification of black carbon internally mixed with secondary organic aerosol, J. Geophys. Res., 110, D19204, doi:19210.11029/12005JD006046, 2005.

Schulz, M., Textor, C., Kinne, S., Balkanski, Y., Bauer, S., Berntsen, T., Berglen, T., Boucher, O., Dentener, F., Guibert, S., Isaksen, I. S. A., Iversen, T., Koch, D., Kirkevåg, A., Liu, X., Montanaro, V., Myhre, G., Penner, J. E., Pitari, G., Reddy, S., Seland, Ø., Stier, P., and Takemura, T.: Radiative forcing by aerosols as derived from the AeroCom present-day and pre-industrial simulations, Atmos. Chem. Phys., 6, 5225-5246, doi:10.5194/acp-6-5225-2006, 2006.

Shine, K. P., Cook, J., Highwood, E. J., and Joshi, M. M.: An alternative to radiative forcing for estimating the relative importance of climate change mechanisms, Geophys. Res. Let., 30, 2047, doi:10.1029/2003g1018141, 2003.

Shine, K. P., Fuglestvedt, J. S., Hailemariam, K., and Stuber, N.: Alternatives to the global warming potential for comparing climate impacts of emissions of greenhouse gases, Clim. Change, 68, 281-302, 2005.

Shindell, D. and Faluvegi, G.: Climate response to regional radiative forcing during the twentieth century, Nat. Geosci., 2, 294 300, doi:10.1038/ngeo473, 2009.
Shindell, D. T., Chin, M., Dentener, F., Doherty, R. M., Faluvegi, G., Fiore, A. M., Hess, P., Koch, D. M., MacKenzie, I. A., Sanderson, M. G., Schultz, M. G., Schulz, M., Stevenson, D. S., Teich, H., Textor, C., Wild, O., Bergmann, D. J., Bey, I., Bian, H., Cuvelier, C., Duncan, B. N., Folberth, G., Horowitz, L. W., Jonson, J., Kaminski, J. W., Marmer, E., Park, R., Pringle, K. J., Schroeder, S., Szopa, S., Takemura, T., Zeng, G., Keating, T. J., and Zuber, A.: A multi-model assessment of pollution transport to the Arctic, Atmos. Chem. Phys., 8, 5353-5372, doi:10.5194/acp-8-5353-2008, 2008.

Shiraiwa, M., Kondo, Y., Moteki, N., Takegawa, N., Miyazaki, Y., and Blake, D. R.: Evolution of mixing state of black carbon in polluted air from Tokyo, Geophys. Res. Let., 34, L16803, doi:16810.11029/12007GL029819, 2007.

Smith, S. J., Wigley, T. M. L., Nakicenovic, N., and Raper, S. C. B.: Climate implications of greenhouse gas scenarios, Tech Forecast Soc Change, 65, 195-204, 2000.

Textor, C., Schulz, M., Guibert, S., Kinne, S., Balkanski, Y., Bauer, S., Berntsen, T., Berglen, T., Boucher, O., Chin, M., Dentener, F., Diehl, T., Easter, R., Feichter, H., Fillmore, D., Ghan, S., Ginoux, P., Gong, S., Grini, A., Hendricks, J., Horowitz, L., Huang, P., Isaksen, I., Iversen, I., Kloster, S., Koch, D., Kirkevg, A., Kristjansson, J. E., Krol, M., Lauer, A., Lamarque, J. F., Liu, X., Montanaro, V., Myhre, G., Penner, J., Pitari, G., Reddy, S., Seland, Ø., Stier, P., Takemura, T., and Tie, X.: Analysis and quantification of the diversities of aerosol life cycles within AeroCom, Atmos. Chem. Phys., 6, 1777-1813, doi:10.5194/acp-61777-2006, 2006.

van der Werf, G. R., Randerson, J. T., Giglio, L., Collatz, C. J., Kasibhatla, P. S., and Arellano Jr., A. F.: Interannual variability in global biomass burning emissions from 1997 to 2004, Atmos. Chem. Phys., 6, 3421-3441, 2006, http://www.atmos-chem-phys.net/6/3421/2006/.

Wild, O., Prather, M. J., and Akimoto, H.: Indirect long-term global radiative cooling from $\mathrm{NO}_{\mathrm{x}}$ emissions, Geophys. Res. Let., 28, 1719-1722, 2001.

Yu, H., Kaufman, Y. J., Chin, M., Feingold, G., Remer, L. A., Anderson, T. L., Balkanski, Y., Bellouin, N., Boucher, O., Christopher, S., DeCola, P., Kahn, R., Koch, D., Loeb, N., Reddy, M. S., Schulz, M., Takemura, T., and Zhou, M.: A review of measurement-based assessments of the aerosol direct radiative effect and forcing, Atmos. Chem. Phys., 6, 613-666, doi:10.5194/acp-6-613-2006, 2006. 